\title{
Impact of spaceborne carbon monoxide observations from the S-5P platform on tropospheric composition analyses and forecasts
}

\author{
Rachid Abida $^{1}$, Jean-Luc Attié ${ }^{1,2}$, Laaziz El Amraoui ${ }^{1}$, Philippe Ricaud ${ }^{1}$, William Lahoz ${ }^{3}$, Henk Eskes ${ }^{4}$, Arjo Segers ${ }^{5}$, \\ Lyana Curier ${ }^{5}$, Johan de Haan ${ }^{4}$, Jukka Kujanpää ${ }^{6}$, Albert Oude Nijhuis ${ }^{4}$, Johanna Tamminen ${ }^{6}$, \\ Renske Timmermans $^{5}$, and Pepijn Veefkind ${ }^{4}$ \\ ${ }^{1}$ CNRM-GAME, Météo-France/CNRS UMR 3589, Toulouse, France \\ ${ }^{2}$ Université de Toulouse, Laboratoire d'Aérologie, CNRS UMR 5560, Toulouse, France \\ ${ }^{3}$ NILU - Norwegian Institute for Air Research, P.O. Box 100, 2027 Kjeller, Norway \\ ${ }^{4}$ Royal Netherlands Meteorological Institute (KNMI), P.O. Box 201, 3730 AE De Bilt, the Netherlands \\ ${ }^{5}$ TNO, Business unit Environment, Health and Safety, P.O. Box 80015, 3508 TA Utrecht, the Netherlands \\ ${ }^{6}$ Finnish Meteorological Institute, Earth Observation Unit, P.O. Box 503, 00101 Helsinki, Finland \\ Correspondence to: Rachid Abida (rachid.abida@meteo.fr)
}

Received: 13 November 2015 - Published in Atmos. Chem. Phys. Discuss.: 1 February 2016

Revised: 13 October 2016 - Accepted: 25 November 2016 - Published: 24 January 2017

\begin{abstract}
We use the technique of Observing System Simulation Experiments (OSSEs) to quantify the impact of spaceborne carbon monoxide $(\mathrm{CO})$ total column observations from the Sentinel-5 Precursor (S-5P) platform on tropospheric analyses and forecasts. We focus on Europe for the period of northern summer 2003, when there was a severe heat wave episode associated with extremely hot and dry weather conditions. We describe different elements of the OSSE: (i) the nature run (NR), i.e., the "truth"; (ii) the CO synthetic observations; (iii) the assimilation run (AR), where we assimilate the observations of interest; (iv) the control run (CR), in this study a free model run without assimilation; and (v) efforts to establish the fidelity of the OSSE results. Comparison of the results from $A R$ and the $\mathrm{CR}$, against the NR, shows that $\mathrm{CO}$ total column observations from S-5P provide a significant benefit (at the $99 \%$ confidence level) at the surface, with the largest benefit occurring over land in regions far away from emission sources. Furthermore, the S-5P CO total column observations are able to capture phenomena such as the forest fires that occurred in Portugal during northern summer 2003. These results provide evidence of the benefit of S-5P observations for monitoring processes contributing to atmospheric pollution.
\end{abstract}

\section{Introduction}

Over the last decade, the capabilities of satellite instruments for sensing the lower troposphere have improved and opened the way for monitoring and better understanding of atmospheric pollution processes, e.g., tropospheric chemistry (Jacob, 2000), long-range transport (HTAP, 2007), and emissions (e.g., Streets, 2013, and references therein). Satellite instruments provide global measurements of many pollutants (e.g., ozone; carbon monoxide, $\mathrm{CO}$; nitrogen dioxide, $\mathrm{NO}_{2}$; aerosols), including information on their transboundary transport, and complement in situ measurements from ground-based stations (e.g., the European Monitoring and Evaluation Programme (EMEP); http://www.nilu.no/ projects/ccc/emepdata.html) and AirBase (http://acm.eionet. europa.eu/databases/airbase/) networks). Low Earth orbit (LEO) satellite platforms have the advantage of providing observations with global coverage, but at a relatively low temporal resolution. Geostationary Earth orbit (GEO) satellite platforms provide observations at a continental scale, i.e., not global, but at a much higher temporal resolution.

Satellite data, either in synergy with ground-based and airborne measurements and/or assimilated into models such as chemistry transport models (CTMs), contribute to an improved understanding of tropospheric chemistry and dynamics and improved forecasts of atmospheric pollutant fields 
(see, e.g., Elbern et al., 2010). As part of an integrated observing strategy, satellite measurements provide a global view on air quality (AQ). The challenge for future spaceborne missions will be to assess directly the local scales of transport and/or chemistry for tropospheric pollutants $(1 \mathrm{~h}$ or less, $10 \mathrm{~km}$ or less) and to facilitate the use of remote sensing information for improving local- and regional-scale (from country-wide to continental scales) AQ analyses and forecasts. Building on this effort, various LEO satellite platforms and/or constellations of GEO satellite platforms will help extend AQ information from continental scales to global scales (e.g., Lahoz et al., 2012, and references therein for LEO/GEO platforms; Barré et al., 2015, for GEO platforms).

An atmospheric species of interest for monitoring $\mathrm{AQ}$ is $\mathrm{CO}$, owing to its relatively long timescale in the troposphere; its distribution provides information on the transport pathways of atmospheric pollutants. Spaceborne instruments on LEO satellite platforms demonstrate the potential of remote sensing from space to determine the $\mathrm{CO}$ distribution and its main emission sources at the global scale (Edwards et al., 2004, 2006; Buchwitz et al., 2006; Warner et al., 2013; Worden et al., 2013; George et al., 2015; Fu et al., 2016, and references therein). These LEO satellite platforms include MOPITT (Measurements Of Pollution In The Troposphere), AIRS (Atmospheric InfraRed Sounder), TES (Tropospheric Emission Spectrometer), IASI (Infrared Atmospheric Sounding Interferometer), and CrIS (Cross-track Infrared Sounder) operating in the thermal infrared (TIR) and SCIAMACHY (SCanning Imaging Absorption spectroMeter for Atmospheric ChartographY) operating in the shortwave infrared (SWIR), respectively. By contrast, to our knowledge, there are no GEO satellite platforms measuring the CO distribution. However, despite their potential, due to limited revisit time, and relatively coarse spatial resolution, LEO instruments are not optimal for monitoring regional and local aspects of air quality.

Copernicus is the current European programme for the establishment of a European capability for Earth observation (http://www.copernicus.eu/pages-principales/services/ atmosphere-monitoring). The main objective of the Copernicus Atmospheric Services is to provide information on atmospheric variables (e.g., essential climate variables; https://www.wmo.int/pages/prog/gcos/index.php?name= EssentialClimateVariables) in support of European policies regarding sustainable development and global governance of the environment. The Copernicus Atmospheric Services cover AQ, climate change/forcing, stratospheric ozone, and solar radiation. The services rely mainly on data from Earth observation satellites.

To ensure operational provision of Earth observation data, the space component of the Copernicus programme includes a series of spaceborne missions developed and managed by the European Space Agency (ESA) and the European Organisation for the Exploitation of Meteorological Satellites (EUMETSAT). Among them, three missions address at- mospheric composition. These are the Sentinel-5 (S-5) and Sentinel-5 Precursor (S-5P) from a LEO satellite platform and the Sentinel-4 (S-4) from a GEO satellite platform. The goal of the $\mathrm{S}-4$ is to monitor key atmospheric pollutants (e.g., ozone; $\mathrm{NO}_{2}$; sulfur dioxide, $\mathrm{SO}_{2}$; bromine monoxide, $\mathrm{BrO}$; formaldehyde) and aerosols at relatively high spatiotemporal resolution over Europe and North Africa $(8 \mathrm{~km} ; 1 \mathrm{~h})$. We expect launch of the S-4 mission in 2021 with a lifetime of 8.5 years. The goal of the S-5 and S-5P platforms is to provide global daily measurements of atmospheric pollutants (e.g., $\mathrm{CO}$, ozone, $\mathrm{NO}_{2}, \mathrm{SO}_{2}, \mathrm{BrO}$, and formaldehyde), climate-related trace gases (e.g., methane, $\mathrm{CH}_{4}$ ), and aerosols, at relatively high spatial resolution (from below $8 \mathrm{~km}$ to below $50 \mathrm{~km}$, depending on wavelength).

The $\mathrm{S}-5 \mathrm{P}$ is the ESA pre-operational mission required to bridge the gap between the end of the OMI (Ozone Monitoring Instrument) and the SCIAMACHY missions and the start of the S-5 mission planned for 2020 onwards. The S-5P scheduled launch is in 2017 with a 7-year design lifetime. The S-5P will fly in an early afternoon sunsynchronous LEO geometry with an Equator crossing mean local solar time of 13:30, chosen to allow the instrument to measure the strong pollution signal present in the afternoon. We describe the TROPOspheric Monitoring Instrument (TROPOMI) onboard S-5P in Sect. 2.2. In contrast, the Infrared Atmospheric Sounding Interferometer (IASI) onboard MetOp platform collects measurements at a local solar time of 09:30 (when the pollution signal is relatively weak) and thus has a lower predictive value (Veefkind et al., 2012, and references therein). The S-5P LEO platform will address the challenge of limited revisit time from LEOs by providing unprecedented high spatial resolution of $7 \times 7 \mathrm{~km}$ and, with its SWIR band, improved sensitivity in the planetary boundary layer (PBL) compared to a TIR instrument such as IASI. The PBL varies in depth throughout the year, but it is contained within the lowermost troposphere (heights 0 $3 \mathrm{~km}$ ) and typically spans the heights $0-1 \mathrm{~km}$.

A method to objectively determine the added value of future satellite observations such as from the S-4, S-5, and S-5P platforms and to investigate the impact of different instrument designs is that of Observing System Simulation Experiments (OSSEs) commonly based on data assimilation (e.g., Lahoz and Schneider, 2014). The OSSEs have been extensively used and shown to be useful in the meteorological community to test the impact of future meteorological observations on the quality of weather forecasts (Nitta, 1975; Atlas, 1997; Lord et al., 1997; Atlas et al., 2003). In a recent paper, Timmermans et al. (2015) review the application of OSSEs to assess future missions to monitor AQ. The OSSEs are increasingly being used by the space agencies to assess the added value of future instruments to be deployed as part of the global observing system (e.g., work on the ESA Earth Explorer ADM-Aeolus; Tan et al., 2007).

Although the usefulness of OSSEs is well established, they have limitations, discussed in Masutani et al. (2010a, b). A 
frequent criticism of OSSEs is that they are overoptimistic, largely due to the difficulties of representing the real Earth system (e.g., the atmosphere), even with state-of-the-art numerical models. Nevertheless, even if overoptimistic, OSSEs provide bounds on the impact of new observing systems. For example, if additional instruments provide no significant impact within an OSSE, they are unlikely to do so in reality.

In this paper, we describe a regional-scale OSSE over Europe for northern summer 2003 (1 June-31 August) to explore the impact of S-5P CO total column measurements on lowermost tropospheric air pollution analyses, with a focus on CO PBL concentrations. The severe heat wave experienced in Europe during northern summer 2003, as well as the concomitant atmospheric pollution and fire episodes, had a strongly negative societal impact, being responsible for the deaths of over 14000 people in France (Vautard et al., 2005). This period had extremely hot and dry weather conditions and the long-lasting atmospheric blocking conditions significantly contributed to the accumulation of pollutants in the PBL due to the extended residence time of the air parcels (Solberg et al., 2008). The spatial distribution of the enhanced levels of $\mathrm{CO}$ and ozone was much more widespread over Europe during that summer than in previous ones (Lee et al., 2006; Ordoñez et al., 2010). These exceptional weather conditions also resulted in several extreme wildfire episodes over the Iberian Peninsula and the Mediterranean coast (Barbosa et al., 2004). Tressol et al. (2008) point out that between 6 and 10 August 2003 the contribution of biomass burning to measured $\mathrm{CO}$ levels in the lowermost troposphere reached $35 \%$ of the total CO field at these levels, a value comparable to typical European anthropogenic emissions which represent $30 \%$ of this total CO field. Thus, the 3-month period of 1 June-31 August 2003 includes both extreme and normal conditions and provides an opportunity to study the full range of pollution levels that occur in a summer season over Europe. A better knowledge of the $\mathrm{CO}$ distribution improves its forecast and allows a better knowledge of the long-range transport of pollution plumes. In addition, because $\mathrm{CO}$ is one of the ozone precursors, information on it likely improves the ozone distribution calculated by the model.

The OSSE study domain covers the larger part of Europe $\left(5^{\circ} \mathrm{W}-35^{\circ} \mathrm{E}, 35-70^{\circ} \mathrm{N}\right)$, and we perform the OSSE simulations at the spatial resolution of $0.2^{\circ}$ (latitude and longitude). This corresponds to a spatial resolution of $\sim 20 \mathrm{~km}$ (meridionally) and $\sim 15 \mathrm{~km}$ (zonally, at $45^{\circ} \mathrm{N}$ ). With this spatial resolution, we can track long-range transport plumes of $\mathrm{CO}$. The length of the study period ensures we can sample different meteorological situations typical for summertime, and it provides an acceptable compromise between run-time restrictions and provision of sufficient information for statistically significant results. The focus of this OSSE is CO concentrations and the goal is to evaluate the benefit of S-5P CO columns after assimilation in a CTM, in particular CO concentrations at the surface.
The structure of the paper is as follows. In Sect. 2 we describe the various components of the OSSE; in Sect. 3 we present the results from the OSSE for S-5P during northern summer 2003 over Europe. Finally, Sect. 4 provides conclusions and identifies further work. A guiding principle in the OSSE setup in this paper is to avoid overoptimistic results.

\section{The OSSE setup}

The OSSE concept consists of simulating observations and their associated errors from a representation of reality (the "nature run" or NR) and providing this information to a data assimilation system to produce estimates of the NR states. Thereafter, one compares these estimates of the NR states from an assimilation run, AR (where the observation of interest has been assimilated), and from a control run, CR (in this case a free model run), against the NR. The performance of the AR and the CR against the NR quantifies the benefit of the observation of interest.

The OSSEs are widely used in the meteorological community for assessing the usefulness of new meteorological satellite data. Recent examples (not exhaustive) include the work of Lahoz et al. (2005), Stoffelen et al. (2006), and Tan et al. (2007); Masutani et al. (2010a) reviews the OSSE methodology and provides a comprehensive list of references of OSSEs for meteorological applications. By contrast, there are relatively few studies concerning OSSEs for AQ applications (Edwards et al., 2009; Timmermans et al., 2009a, b; Claeyman et al., 2011; Zoogman et al., 2011, 2014a, b; Yumimoto, 2013). In a recent review, Timmermans et al. (2015) comment that documented AQ OSSEs have demonstrated the benefits that could accrue from proposed and planned satellite platforms for AQ monitoring and forecasting. In the study described in this paper, the setups for the NR, the CR, and the AR use different models, thereby avoiding the identical twin problem typically associated with overly optimistic OSSE results (see, e.g., Masutani et al., 2010a). In Sect. 2.1-2.5 we describe the various elements of the OSSE study described in this paper. Figure 1 provides a schematic showing the relationships between the various elements in an OSSE. In this study, we use the LOTOS-EUROS model as the NR and the MOCAGE (Modèle de Chimie Atmosphérique de Grande Echelle) CTM as the CR (for details of these models, see Sect. 2.1 and 2.4 , respectively)

\subsection{The nature run}

A key element of an OSSE is the NR that defines the true state used to evaluate analyses and/or forecasts using simulated observations. The NR commonly consists of a long, free-running forecast evolving continuously in a dynamically consistent way (Masutani et al., 2010a, b). For this study, the basis of the NR consists of two high-resolution free model simulations performed with (i) the regional LOTOS-EUROS 


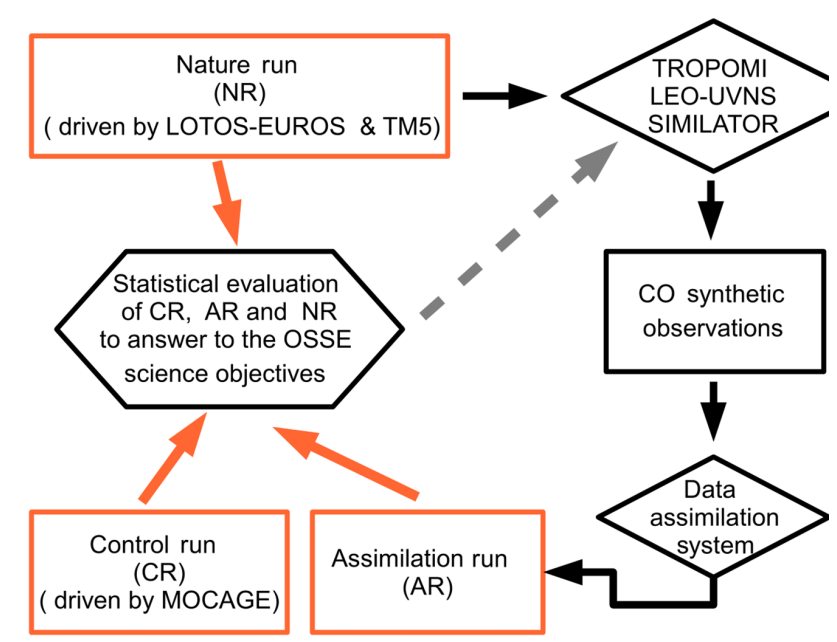

Figure 1. Diagram of the Observing System Simulation Experiments (OSSE) components (see text for details of each of the elements).

air quality model (Schaap et al., 2008) and (ii) the global chemistry transport model TM5 (Huijnen et al., 2010). We obtain the NR by combining the LOTOS-EUROS CO profiles from the surface to $3.5 \mathrm{~km}$ with the TM5 CO profiles from $3.5 \mathrm{~km}$ to the top of the atmosphere (identified by the TM5 model top at $0.1 \mathrm{hPa}$ ). We use spatial interpolation to merge the values near the boundary between the two models at a height of $3.5 \mathrm{~km}$. The model simulations used to construct the NR have a spinup period of 3 months. We archive the NR output data on an hourly basis.

To construct the NR, we run the LOTOS-EUROS model at a horizontal resolution of about $7 \mathrm{~km}$ nested into the TM5 model, the latter run with a zoom domain over Europe at $1 \times 1^{\circ}$ resolution. The TM5 model has 34 layers with a model top at $0.1 \mathrm{hPa}$. The LOTOS-EUROS model describes air pollution in the lowermost troposphere. It has four vertical layers following the dynamic mixing layer approach. The first layer is a fixed surface layer of $25 \mathrm{~m}$ thickness, the second layer (boundary layer) follows the mixing layer height, and there are two reservoir layers spanning the rest of the atmosphere up to $3.5 \mathrm{~km}$. The implicit assumption of the LOTOSEUROS model is the presence of a well-mixed boundary layer, so constituent concentrations are constant up to the top of the PBL. The meteorological data used as input for the LOTOS-EUROS model come from the European Centre for Medium-Range Weather Forecasts (ECMWF). Prescription of surface anthropogenic emission is from the TNO-MACCII emission database (Kuenen et al., 2014), and fire emissions are from the MACC global fire assimilation system (GFAS v1; Kaiser et al., 2012).

In the design of an OSSE, it is important to demonstrate that the NR exhibits the same statistical behavior as the real atmosphere in every aspect relevant to the observing system under study (Masutani et al., 2010a, b). For the LOTOS-
EUROS model used to build the lowermost levels of the $\mathrm{NR}$, there is extensive verification by comparison with European data and by frequent participation in international model comparisons. This is the case for ozone and particulate matter (see Hass et al., 2003; Cuvelier et al., 2007; van Loon et al., 2007; Stern et al., 2008; Manders et al., 2009; Curier et al., 2012; Marécal et al., 2015). To evaluate the NR, we compare the surface $\mathrm{CO}$ data to available in situ groundbased $\mathrm{CO}$ measurements over Europe during northern summer 2003 (1 June-31 August). For this comparison, we use the ground-based stations from the AirBase database. We consider all types of ground-based stations from this database because of the limited number of available measurements, but we discard stations with less than $75 \%$ of hourly data within a month. This provides 171 ground-based stations for the comparison against the NR (note this approach results in a paucity of stations over France).

Figure 2 shows the location of the selected AirBase ground-based stations measuring $\mathrm{CO}$ over Europe during northern summer 2003 (top panel) and the time series of CO concentrations during 1 June-31 August 2003, measured by the selected AirBase ground-based stations and simulated by the NR and the CR (bottom panel - see Sect. 2.4 for the definition of the CR). Note that most ground-based stations selected are located in polluted areas, where big emission sources of $\mathrm{CO}$ are present. We form the time series from the ground-based stations by averaging spatially over all the sites. We form the NR time series similarly but interpolate the NR surface data to the station location. We do not add random observation errors to the NR time series.

From Fig. 2, we see that, generally, the NR captures reasonably well the features of observed $\mathrm{CO}$ temporal variability during the three phases characterizing the summer of 2003: before, during, and after the heat wave (the heat wave occurred on 31 July-15 August). One can notice that the observed and simulated CO time series exhibit some highfrequency components due principally to the fact that the 171 sites representing these time series are mostly located in emission source areas (there are only 5 background rural sites among the 171 sites selected). The CO diurnal pattern over a background rural site during the course of a summer day shows a peak between 07:00 and 08:00 in the morning. However, in polluted regions, the $\mathrm{CO}$ diurnal pattern shows more variability. The correlation coefficient, $\rho$, between the ground-based data and NR time series shown in the middle panel is 0.71 . From this we conclude that the NR has a realistic representation of the $\mathrm{CO}$ diurnal cycle. Note that $\mathrm{CO}$ concentration levels in the NR are slightly lower than observed ones. The bias of the NR with respect to observed $\mathrm{CO}$ concentrations fluctuates around $-10 \%$ on average during normal conditions and reaches $-20 \%$ within the heat wave period. This means that the NR reproduces the surface concentrations with a negative bias (NR lower than groundbased stations) between 10 and $20 \%$. Nonetheless, the simulated $\mathrm{CO}$ concentrations and those measured by the ground- 

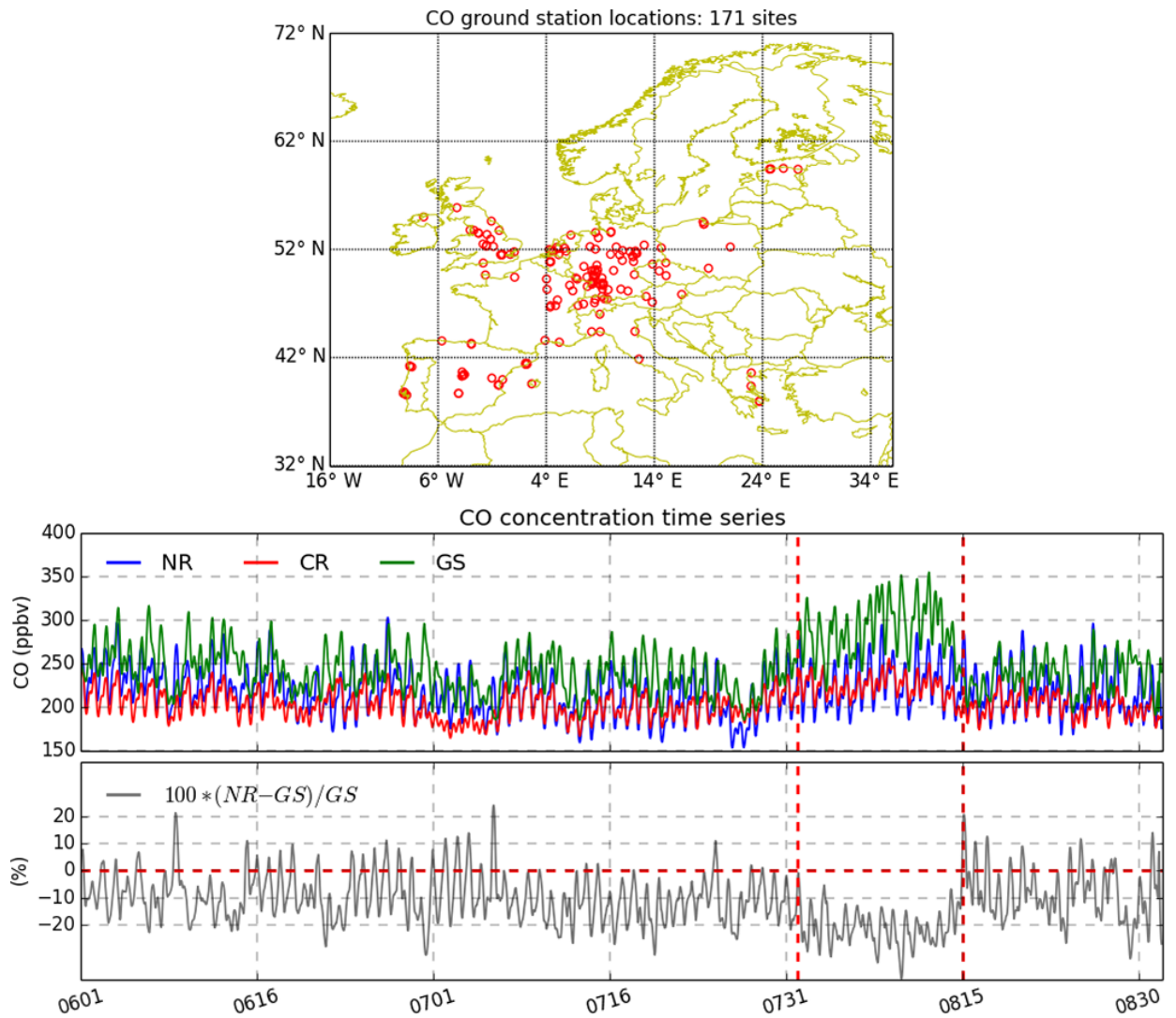

Figure 2. Top panel: location of selected ground-based stations for $\mathrm{CO}$ measurements taken from the AirBase database during northern summer 2003 (1 June-31 August). There are 171 sites with locations shown by circles. The labels show longitude in degrees ( $x$ axis) by latitude in degrees ( $y$ axis). Middle panel: simulated and measured time series of CO concentrations in surface air from nature run (blue line), the control run (red line), and the selected 171 AirBase sites (green line). We form the CO time series for the ground-based stations by averaging the hourly data representative of the 171 sites. The labels show time in MMDD format ( $x$ axis) by CO concentration in parts per billion by volume, ppbv ( $y$ axis). Bottom panel: the grey curve shows the relative error of the nature run (NR) with respect to the observations, defined as NR value minus ground station value divided by the ground station value and multiplied by 100 . The labels show time in MMDD format ( $x$ axis) by relative error in percent ( $y$ axis). The vertical red dashed lines in the middle and bottom panels delineate the 2003 European heat wave period (31 July-15 August).

based stations generally fall within the same range of values (between 200 and $400 \mathrm{\mu g} \mathrm{m}^{-3}$ ). Thus, for the OSSE period considered, we conclude that the NR is representative of the variability of actual observations over the European domain, albeit with a negative bias.

Additionally, from Fig. 2 the behavior of the $\mathrm{CO}$ time series from the CR compared to the NR is similar to the behavior of the NR CO time series compared to the AirBase data. This suggests that the NR from LOTOS-EUROS model from which we sample the S-5P simulated observations is reasonably realistic. This reduces the likelihood that the OSSE produces overoptimistic results.

\subsection{The S-5P CO simulated measurements}

The S-5P will deploy the TROPOMI jointly developed by the Netherlands and ESA (Veefkind et al., 2012). The TROPOMI instrument has heritage from both the OMI and the SCIA-
MACHY missions. The TROPOMI instrument will make measurements in the UV-visible wavelength range (270 $500 \mathrm{~nm}$ ), the near infrared (NIR, 675-775 nm), and the SWIR $(2305-2385 \mathrm{~nm})$. It will deliver a key set of gas and aerosol data products for air quality and climate applications, including ozone, $\mathrm{NO}_{2}$, formaldehyde, $\mathrm{SO}_{2}$, methane, and $\mathrm{CO}$.

To enable sounding of the lower atmosphere at finer scales, TROPOMI has an unprecedented spatial resolution of $7 \times$ $7 \mathrm{~km}^{2}$ at nadir. This relatively high spatial resolution is necessary for air quality applications at local to regional scales. It will resolve emission sources with $15 \%$ of accuracy and $10 \%$ precision (Veefkind et al., 2012) and will obtain an acceptable fraction of cloud-free spectra. In contrast to the advantages provided by the relatively high spatial resolution of $\mathrm{S}-5 \mathrm{P}$ and design improvements, the SCIAMACHY CO data need averaging in time (roughly 1 month) and space $\left(5 \times 5^{\circ}\right)$ to obtain realistic $\mathrm{CO}$ distributions at comparable uncertainty (Galli et al., 2012). Furthermore, TROPOMI (Landgraf et al., 
Table 1. Spectral and radiometric settings for DISAMAR and the lookup table node points.

\begin{tabular}{ll}
\hline & Spectral and radiometric settings \\
\hline Spectral range (nm) & $2330-2345$ \\
Spectral resolution (FWHM) (nm) & 0.25 \\
Spectral sampling (nm) & 0.1 \\
SNR Earth radiance & 120 \\
SNR solar irradiance & 5000 \\
Additional calibration error (\%) & 1.0, correlation length $100 \mathrm{~nm}$ \\
\hline & \multicolumn{1}{c}{ Node points } \\
\hline cos(SZA) & $0.1-1.0$, step 0.1 \\
cos(VZA) & $0.3-1.0$, step 0.1 \\
Relative azimuth (degree) & $0.0,180.0$ \\
Cloud-surface pressure (hPa) & $1100-200$, step -100 \\
Cloud-surface albedo & $0.0,0.005,0.01,0.02,0.04,0.06,0.1,0.2,0.3,0.4,0.8,0.9$ \\
Pressure layers (hPa) & $1100,1000,900,800,700,600,500,400,300,200,137.50$, \\
& $68.75,34.38,17.19,8.59,4.30,2.15,1.07,0.54,0.27,0.13,0.07$ \\
\hline
\end{tabular}

2016) will have a wide swath of $2600 \mathrm{~km}$ to allow for daily global coverage. The relatively high radiometric sensitivity of S-5P will allow measurements at low albedo (order of $2 \%$; Veefkind et al., 2012), thus helping track smaller pollution events and improving the accuracy of air quality assessments and forecasts. The use of S-5P CO total column measurements with inverse modeling techniques will also help quantify biomass burning emissions and map their spatial distribution. The simultaneous measurements of $\mathrm{CO}$ and, for example, $\mathrm{NO}_{2}$ will provide additional information on wildfires and other pollution episodes (Veefkind et al., 2012).

We use the NR results to generate a set of synthetic S-5P observations. This involves several steps: (1) generating realistic S-5P orbits and geolocation and viewing/solar geometries for the appropriate overpass time; (2) using the ECMWF modeled cloud distributions to generate effective cloud fractions; (3) generating lookup tables for the averaging kernels and observation errors; (4) collocation and application of the NR to derive a set of synthetic observations for 3 summer months and 3 winter months. We discuss these steps in the subsections below.

\subsubsection{Orbit simulator}

We use the System Tool Kit (STK, available from AGI, http://www.agi.com/products/) to generate the S-5P orbit geometry and the geolocation of the edges of the swath as a function of time. Based on these characteristics, we generate the location of the individual observations with a spatial distance of $7 \mathrm{~km}$. We apply time and longitude shifts to the STK-generated orbits to obtain the orbits for the 3 summer and 3 winter months of this study. Subsequently, we compute the solar and viewing geometries. Finally, we maintain segments of the orbits that have an overlap with the modeling domain.

\subsubsection{Cloud properties}

We obtain cloud fields from the high-resolution operational weather forecast archive of the ECMWF. We retrieve meteorological fields of liquid water content, ice water content, specific humidity, and cloud fraction at a resolution of $0.25 \times$ $0.25^{\circ}$ for June-August and November 2003-January 2004. We convert these quantities to cloud optical properties. The optical properties determine the reflectance, and we use them to estimate effective cloud fractions and effective cloud top heights as retrieved from the satellite observations (Acarreta et al., 2004). We compare the distribution of effective cloud fractions with the distribution of effective cloud fractions obtained from OMI observations and find a reasonable agreement for summer and winter months. We derive the cloud fractions at the resolution of the ECMWF $0.25 \times 0.25^{\circ}$ grid. This is close to $30 \times 30 \mathrm{~km}^{2}$ at the Equator and decreases as a function of latitude. The ground pixel of OMI UV-2 and visible channels is $13 \times 24 \mathrm{~km}^{2}$ at nadir, increasing to $13 \times 128 \mathrm{~km}^{2}$ at edges of the swath. We consider that the ECMWF grid cells and OMI pixels are of comparable size for comparing the cloud fraction distributions (close to 0.5 million pixels or cells in each distribution). We model clouds as simple Lambertian reflectors and ignore any wavelength dependency of cloud fraction.

We use these effective cloud fractions (and corresponding cloud radiance fractions) to provide weights to the cloud-free and cloud-covered fractions of the surface scene. We use the cloud altitude for the computation of the averaging kernel.

\subsubsection{Averaging kernel and measurement uncertainty lookup tables}

Because of the large number of observations that will become available from the $\mathrm{S}-5 \mathrm{P}$ instrument, full radiative transfer calculations for each observation separately are not fea- 


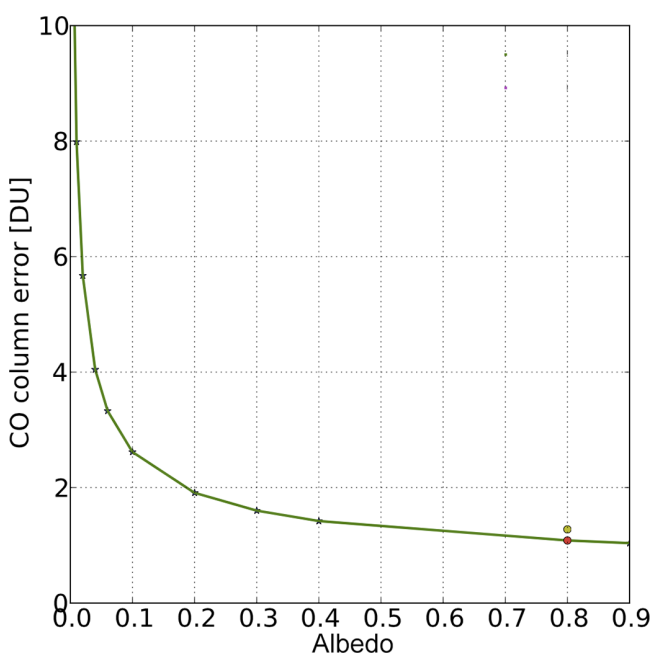

Figure 3. Dependence of the CO column uncertainty (Dobson unit) on the surface albedo. Simulation settings are solar zenith angle $53^{\circ}$, viewing zenith angle $26^{\circ}$ relative azimuth angle $0^{\circ}$, and cloudsurface pressure $1100 \mathrm{hPa}$.

sible. We thus choose to build lookup tables for a set of geometries based on a radiative transfer code that employs the adding-doubling method in combination with optimal estimation (using the radiative transfer toolbox DISAMAR; de Haan, 2012). Lookup tables are set up for the averaging kernels (1-D vectors as a function of altitude) and the measurement uncertainty. Results are stored for a number of surface albedos, cloud-surface pressures, solar zenith angles, viewing zenith angles, and relative azimuth angles. We provide the lookup table details in Table 1. We provide the kernels on 21 pressure levels between 1050.0 and $0.1 \mathrm{hPa}$. We specify the uncertainties for clear-sky and cloudy-sky separately.

Each simulation with DISAMAR consists of a forward calculation of the satellite-observed spectrum, followed by a retrieval step based on the optimal estimation method (Rodgers, 2000). We convert instrument noise, listed in Table 1, into uncertainties for the retrieved CO column. We take a priori trace gas profiles from the CAMELOT study (Levelt et al., 2009). As indicated above, we assume that both the cloud and the surface are Lambertian reflectors. Kujanpää et al. (2015) provide further details of this procedure.

The albedo is a major influence on the uncertainty because it directly determines the signal observed by the instrument. We show this dependence in Fig. 3. Over land, albedo values are typically of the order of 0.1-0.2, with typical column errors of the order of $2 \mathrm{DU}$, or about $10^{17}$ molecules $\mathrm{cm}^{-2}$. Because typical CO columns over Europe are $2 \times 10^{18}$ molecules $\mathrm{cm}^{-2}$, this is a relatively small error of the order of $5 \%$. These numbers are in good agreement with the results presented in the CO ATBD of TROPOMI (document available from https://sentinel.esa.int/web/sentinel/user-guides/ sentinel-5p-tropomi/document-library). Over the ocean, the albedo is very low, and the noise dominates the signal. To simulate this behavior in a realistic way we have added the albedo values $0.005,0.01$, and 0.02 to the albedo list in the lookup tables.

We note that the uncertainties reported here are substantially lower than reported for SCIAMACHY (e.g., Gloudemans et al., 2008). This reflects a difference in specifications of the instruments, and the fact ice buildup on the detectors affected the SCIAMACHY observations. Real TROPOMI observations will show whether the result that these are relatively small errors is realistic.

\subsubsection{Synthetic observations generation}

The generation of the synthetic observations consists of the following steps:

- Co-location of the nature run vertical profiles of $\mathrm{CO}$ to the locations of the observations.

- Computation of the effective cloud fraction, cloud radiance fraction, and cloud pressure from the ECMWF cloud fields co-located to the observations.

- Co-location of the NIR albedo map (surface albedo at $2300 \mathrm{~nm}$ is interpolated from a climatology provided by SRON (Space Research Organisation Netherlands) and based on SCIAMACHY observations; P. Tol, personal communication, 2015) to the locations of the observations.

- Extract interpolated values for the observation kernel and uncertainties from the lookup table.

- Compute the synthetic observation from the inner product of the kernel with the nature run CO profile. We do this for both a clear sky and a fully cloudy situation, using the cloud pressure.

- Add random noise amount to each observation by drawing numbers from a Gaussian distribution with a width determined from the uncertainty estimate.

- Compute the partially clouded synthetic observation by weighting the clear and cloudy results with the cloud radiance fraction (Vidot et al., 2011; Landgraf et al., 2016).

Over land, and in clear-sky cases, the averaging kernel is close to 1 , showing that the $\mathrm{S}-5 \mathrm{P}$ instrument is observing the vertical column to a good approximation (see Fig. 4). In cloud-covered cases the kernel equals 0 for layers below the cloud pressure (yellow line in Fig. 4). For low-albedo cases (over ocean), Rayleigh scattering becomes non-negligible, and the kernel decreases towards the surface, but the noise is dominant in this case.

We show the results of this process in Fig. 5. The figure demonstrates the high resolution of the NR (about $7 \mathrm{~km}$ ) 

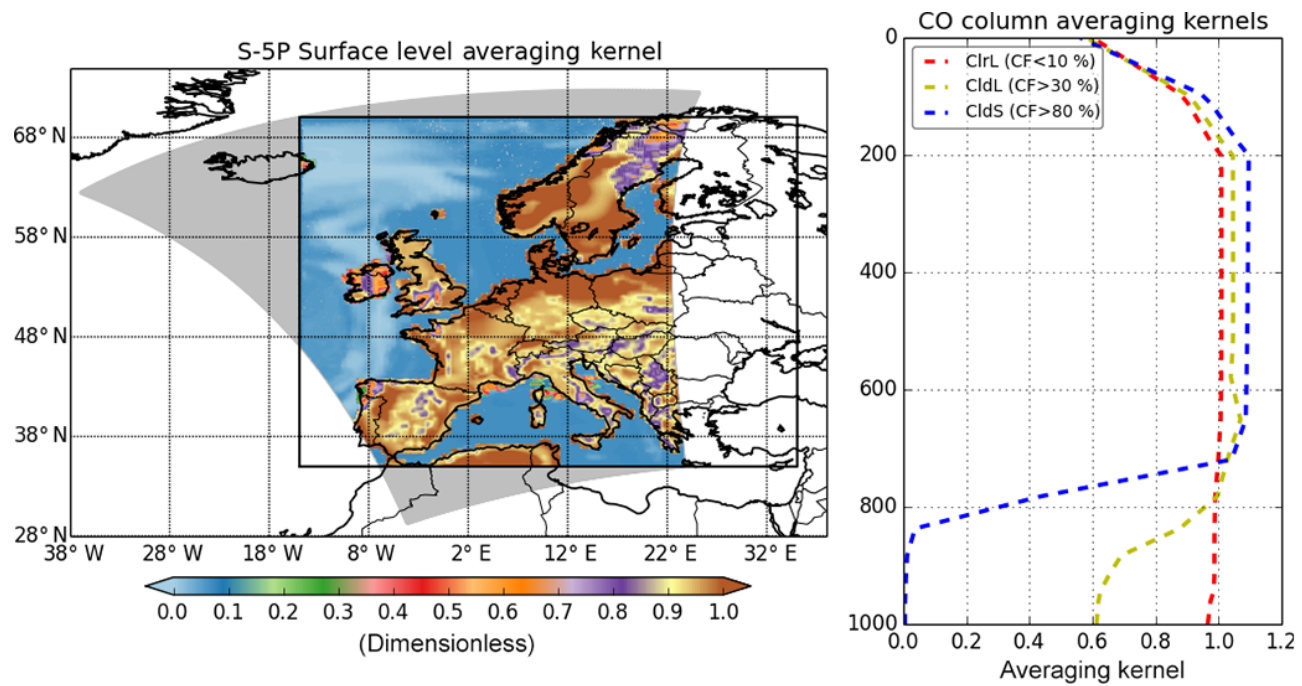

Figure 4. Left panel: S-5P CO averaging kernel values at the surface. Labels are longitude in degrees ( $x$ axis) by latitude in degrees ( $y$ axis). Right panel: averaging kernels for land pixels with cloud fraction less than $10 \%$ (dashed red lines), for land pixels with cloud fraction greater than $30 \%$ (dashed yellow lines), and for sea pixels with cloud fraction greater than $80 \%$ (dashed blue lines). The averaging kernels are for an average of the data shown on the swath for 1 June 2003 at 12:34 UTC. Labels are averaging kernel, normalized ( $x$ axis) by pressure level in $\mathrm{hPa}$ ( $y$ axis).

and the corresponding simulated amount of detail. The bottom panel shows the corresponding $\mathrm{CO}$ observations. Over land, the NR features are clearly present due to the relatively low uncertainty. Over the ocean and Mediterranean, noise dominates the signal. We observe an improved information content near Iceland, related to thick cloud cover, where the higher signal reduces the relative noise.

\subsection{Pre-processing of S-5P CO total column observations}

This section describes the pre-processing of S-5P CO total column observations prior to assimilation into the MOCAGE model (Peuch et al., 1999) for the OSSE simulations. Using the MOCAGE model for the AR and CR simulations avoids the identical twin problem associated with using the same model for both the NR and the OSSE simulations, which typically produces overoptimistic results (Arnold Jr. and Dey, 1986; Stoffelen et al., 2006). Section 2.4 provides further details of the MOCAGE model.

The S-5P will produce large amounts of data due to its wide swath and relatively high spatial resolution of about $7 \times 7 \mathrm{~km}^{2}$. Thus, a pre-processing step is necessary to reduce the data volume for the data assimilation experiments. For this study, we consider only pixels inside the OSSE simulation domain (note that retrieval pixels in each single crosstrack are essentially instantaneous measurements of $\mathrm{CO}$ ). This has the advantage of alleviating the data volume burden. However, a single cross-track over Europe could have more than 80000 valid retrieval pixels. Furthermore, each individual pixel is associated with an averaging kernel vector given at 34 vertical pressure levels, from the surface up to the top of the atmosphere (identified as $0.1 \mathrm{hPa}$ ).

Figure 4 shows an example of averaging kernels at the surface, as well as the averaging kernels representative of retrievals including pixels with different cloud fractions (less than $10 \%$, greater than $30 \%$, and greater than $80 \%$ ). In addition, we discard data points with standard deviation exceeding $20 \%$ of the retrieval or with solar zenith angles larger than $80 \%$. The retrieval over sea is noise dominated. Because of this, we only consider CO partial columns above cloudy sea scenes with cloud fraction more than $80 \%$ and cloud top heights between the surface and $650 \mathrm{hPa}$. Finally, we apply a spatially weighted mean to bin the measurements into $0.2^{\circ} \times 0.2^{\circ}$ grid boxes $\left(\sim 20 \times 15 \mathrm{~km}\right.$ at $\left.45^{\circ} \mathrm{N}\right)$, the assimilation model resolution; this is the setup used for the OSSE assimilation experiments (CR and AR), and is described in El Amraoui et al. (2008a). It combines the MOCAGE model and the PALM (Projet d'Assimilation par Logiciel Multiméthode) data assimilation module. Section 2.4-2.5 provide further details of the CR and AR setups.

The weighted mean for pixels falling in the same model grid box is

$\widetilde{c}=\frac{\sum_{i} w_{i} c_{i}}{\sum_{i} w_{i}}$,

where $\tilde{c}$ is the weighted average, $c_{i}$ is a single column measurement, and $w_{i}\left(=1 / \sigma_{i}^{2}\right)$ is the inverse of the variance corresponding to measurement $c_{i}$ and the weight assigned to this single measurement. The inverse of the variance associated 

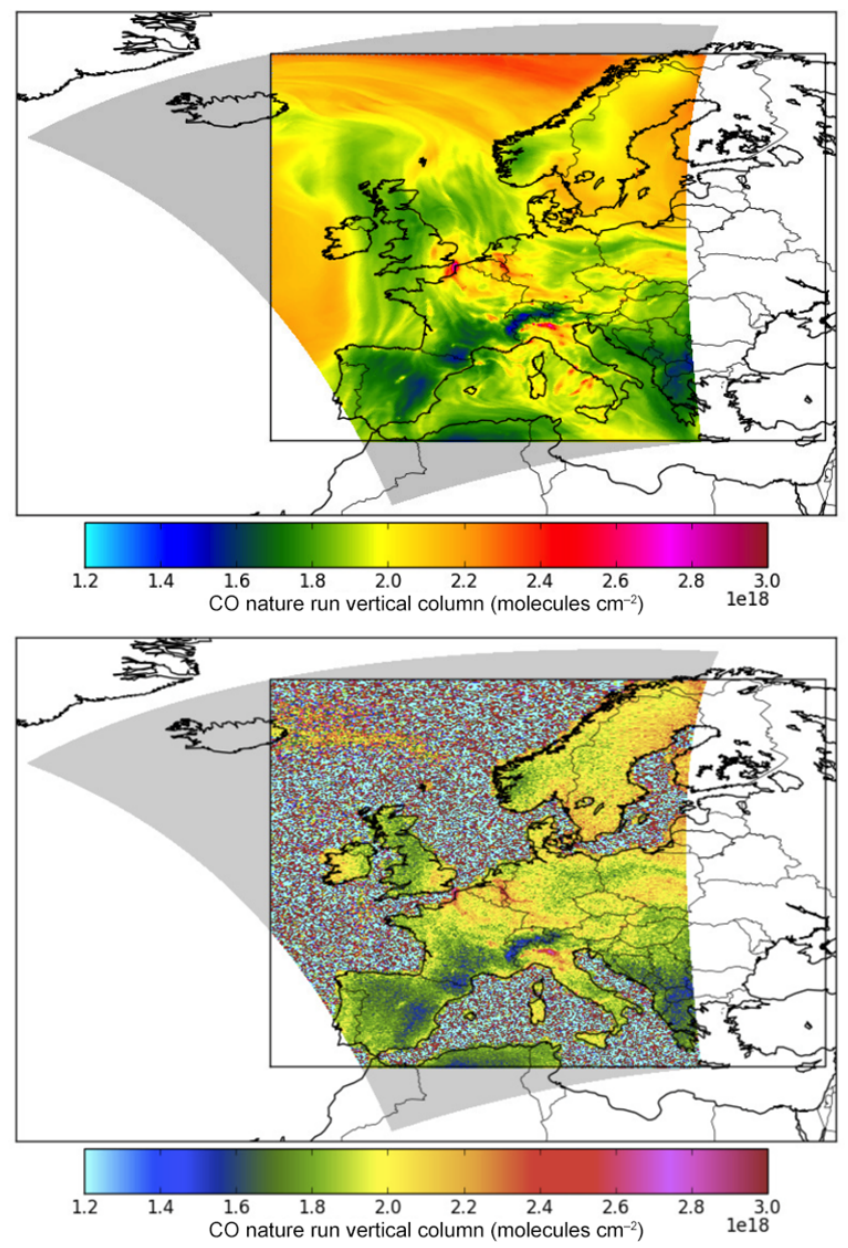

Figure 5. Top: nature run co-located to the synthetic S-5P observations for the 12:34 orbit on 1 June 2003. Bottom: corresponding synthetic observations.

with the weighted average is

$$
\frac{1}{\widetilde{\sigma}^{2}}=\sum_{i} w_{i}
$$

The spatial binning not only reduces considerably the data volume but also results in an improved spatial representativeness of the $\mathrm{CO}$ measurements by reducing the random error of each data pixel.

\subsection{The control run}

To generate the CR, it is important to use a state-of-theart modeling system, which simulates the observational data representing, for example, a current operational observational system. An important requirement for an effective OSSE is to generate the CR with a model different from the one used to construct the NR to avoid the identical twin problem (see Sect. 2.3). If the model from which we extract hypothetical observations is the same as the assimilating model, the OSSE results tend to show unrealistic observation impact and overly optimistic forecast skill (Arnold Jr. and Dey, 1986; Stoffelen et al., 2006). Consequently, by using two independent models the OSSE will simulate more realistically the assimilation of real observations. This allows us to design an OSSE that is not too overoptimistic.

In this OSSE study, the CR is a free model run using MOCAGE. The MOCAGE model is a three-dimensional CTM developed at Météo France (Peuch et al., 1999) providing the evolution of the atmospheric composition in accordance with dynamical, physical, and chemical processes. It provides a number of configurations with different domains and grid resolutions, as well as various chemical and physical parameterization packages. Current use of MOCAGE includes several applications: e.g., the Météo-France operational chemical weather forecasts (Dufour et al., 2004), the Monitoring Atmospheric Composition and Climate (MACC) services (http://www.gmes-atmosphere.eu; Marécal et al., 2015), and studies of climate trends of atmospheric composition (Teyssèdre et al., 2007). Validation of MOCAGE simulations against a large number of measurements took place during the Intercontinental Transport of Ozone and Precursors (ICARTT/ITOP) campaign (Bousserez et al., 2007).

In this study, we use a two-way nesting configuration to generate the $\mathrm{CR}$ and the AR (we describe the AR setup in Sect. 2.5): a global grid with a horizontal resolution of $2 \times 2^{\circ}$ and a regional grid $\left(5^{\circ} \mathrm{W}-35^{\circ} \mathrm{E}, 35-70^{\circ} \mathrm{N}\right)$ with a horizontal resolution of $0.2 \times 0.2^{\circ}$. The MOCAGE model includes 47 sigma-hybrid vertical levels from the surface up to $5 \mathrm{hPa}$. The vertical resolution is 40 to $400 \mathrm{~m}$ in the boundary layer (seven levels) and approximately $800 \mathrm{~m}$ near the tropopause and in the lower stratosphere. The chemical scheme used is RACMOBUS, which combines the stratospheric scheme REPROBUS (REactive Processes Ruling the Ozone BUdget in the Stratosphere; Lefèvre et al., 1994) and the tropospheric scheme RACM (Regional Atmospheric Chemistry Mechanism; Stockwell et al., 1997). The RACMOBUS scheme includes 119 individual species, of which 89 are prognostic variables, and considers 372 chemical reactions.

We force the CR (and the AR) every $3 \mathrm{~h}$ with the ARPEGE analysis (Courtier et al., 1991). We prescribe the surface anthropogenic emission using the MACC-I emission database (https://gmes-atmosphere.eu/about/project structure/input_data/d_emis/). We do not include the fire emissions in the CR and AR experiments described in this paper, as their a priori distribution is unknown. This means that any signature of fire emissions in the AR (see Sect. 2.5) can only come from assimilation of the $\mathrm{CO}$ measurements. Note that for the NR, the surface anthropogenic emissions come from the MACC-II inventory, which helps to differentiate the CR from the NR. Similar to the NR, the CR has a spinup period of 3 months. 


\subsection{The assimilation run}

We assimilate simulated S-5P total column CO observations derived from the LOTOS-EUROS NR into the MOCAGE CTM at a $0.2^{\circ}$ spatial resolution using the MACC extended domain $\left(5^{\circ} \mathrm{W}-35^{\circ} \mathrm{E}, 35-70^{\circ} \mathrm{N}\right)$. The assimilation system used in this study is MOCAGE-PALM (e.g., El Amraoui et al., 2008a) developed jointly by Météo-France and CERFACS (Centre Européen de Recherche et de Formation Avancée en Calcul Scientifique) in the framework of the ASSET European project (Lahoz et al., 2007b). The assimilation module used in this study is PALM, a modular and flexible software, which consists of elementary components that exchange the data (Lagarde et al., 2001). It manages the dynamic launching of the coupled components (forecast model, algebra operators, and input/output of observational data) and the parallel data exchanges. Massart et al. (2009) used the assimilation system MOCAGE-PALM to assess the quality of satellite ozone measurements. The MOCAGE-PALM assimilation system also helps identify and overcome model deficiencies. In this context, its assimilation product has been used in many atmospheric studies in relation to ozone loss in the Arctic vortex (El Amraoui et al., 2008a), tropicsmidlatitudes exchange (Bencherif et al., 2007), stratospheretroposphere exchange (Semane et al., 2007), and exchange between the polar vortex and midlatitudes (El Amraoui et al., 2008b). For this OSSE, to speed up the assimilation process we use the 3D-Var version of PALM. In the OSSE, the MOCAGE model provides the CR and by assimilating the simulated CO data from the NR it provides the AR. Thus, we produce the $\mathrm{CR}$ and $\mathrm{AR}$ outputs with a model different from that used to produce the NR (see Sect. 2.1).

A key element of the data assimilation system is the background error covariance matrix (the $\mathbf{B}$ matrix) (Bannister, 2008). It has a large impact on the 3D-Var analysis used in this study and, thus, it is important to use a form of $\mathbf{B}$ that is as realistic as possible. In MOCAGE-PALM, we base the B-matrix formulation on the diffusion equation approach (Weaver and Courtier, 2001). It can be fully specified by means of the 3-D standard deviation field (square root of the diagonal elements of $\mathbf{B}$, in concentration units or as a percentage of the background field) and 3-D fields of the horizontal $\left(L_{x}\right.$ and $\left.L_{y}\right)$ and vertical $\left(L_{z}\right)$ local correlation length scales. We can estimate the $\mathbf{B}$-matrix elements more efficiently using an ensemble method (Bannister, 2008). This technique consists of feeding an ensemble of states through the data assimilation system to simulate the important sources of error. However, this approach is time consuming and, therefore, not used in this study.

For this study, we use a simple parameterization for the B matrix, where $L_{x}$ and $L_{y}$ are assumed homogeneous and equal to $35 \mathrm{~km}$ (about two model grid lengths) and $L_{z}$ is constant and set to one vertical model layer. As in Emili et al. (2014), the background standard deviation 3-D field is parameterized as a vertically varying percentage of the back- ground profile, which decreases from values of $25 \%$ at the surface to values of $15 \%$ in the upper troposphere and decreases further throughout the stratosphere to values of $5 \%$ in the upper stratosphere (not shown). We base these settings on several 1-day assimilation trials; they ensure reasonable values of standard self-consistency tests, e.g., providing chi-squared $\left(\chi^{2}\right)$ values close to 1 (see Fig. 6 in Sect. 3.1). Furthermore, a value of $L_{x}$ and $L_{y}$ of $35 \mathrm{~km}$ corresponds to more than one grid length of the model, allowing the model to resolve these features. The data assimilation procedure will weight both the observations and the model $1 \mathrm{~h}$ forecasts (from the last analysis point) and will update locations not coincident with the observations through the correlation length scales. Table 2 summarizes the parameters used for the assimilation experiments.

\section{Results}

\subsection{Evaluation of the assimilation run}

In this section, we evaluate the impact of the assimilation of the S-5P CO total column. First, we evaluate the consistency of the assimilation run by separating the clear-sky pixels from their cloudy counterparts (Sect. 3.1.1). Second, to further understand the impact on the surface $\mathrm{CO}$ field of the simulated S-5P CO total column measurements, we investigate the analysis increment $(\delta x)$ to provide a quantitative diagnostic of the quality of the analysis for a selected date, 15 June 2003 (Sect. 3.1.2).

\subsubsection{Consistency of the assimilation run}

We perform two OSSEs. The first one includes all pixels in the OSSE domain, regardless of whether they are cloudy or clear-sky, and the second only includes clear-sky pixels. We consider a pixel to be clear when the cloud fraction is less than $10 \%$. Comparison of the ARs from these two OSSEs indicates that the impact of including all pixels is small. The largest differences between the respective ARs in relation to the NR are $4 \%$ in regions over northern Europe (North Sea and Scandinavia), with the AR for clear-sky pixels closer to the NR (not shown). We can explain these results by the fact the summer generally has low amounts of cloud. Consequently, we only present the results from the OSSE with all pixels.

To evaluate the AR, we calculate the $\chi^{2}$ diagnostic associated with the observation minus forecast $(\mathrm{OmF})$ differences (see, e.g., Lahoz et al., 2007a). Here, we normalize the OmF differences by the background error. We also calculate histograms of the observation minus analysis (OmA) differences, the observation and the simulation from the CR (observation minus control run, hereafter $\mathrm{OmC}$ ) differences, and the OmF differences. We use the observational error to normalize the differences building the histograms of OmA, $\mathrm{OmC}$, and $\mathrm{OmF}$. 
Table 2. Description of the configuration used in the assimilation system.

\begin{tabular}{ll}
\hline & Description \\
\hline Assimilation & 3D-Var, 1 h window \\
Background standard deviation & As \% of the background field (vertically variable) \\
Background correlation zonal length scale $\left(L_{x}\right)$ & Constant, 35 km \\
Background correlation meridional length scale $\left(L_{y}\right)$ & Constant, 35 km \\
Background correlation vertical length scale $\left(L_{z}\right)$ & One vertical model layer \\
S-5P total column CO observation errors & From retrieval product and weighted to account for the \\
& total column \\
\hline
\end{tabular}
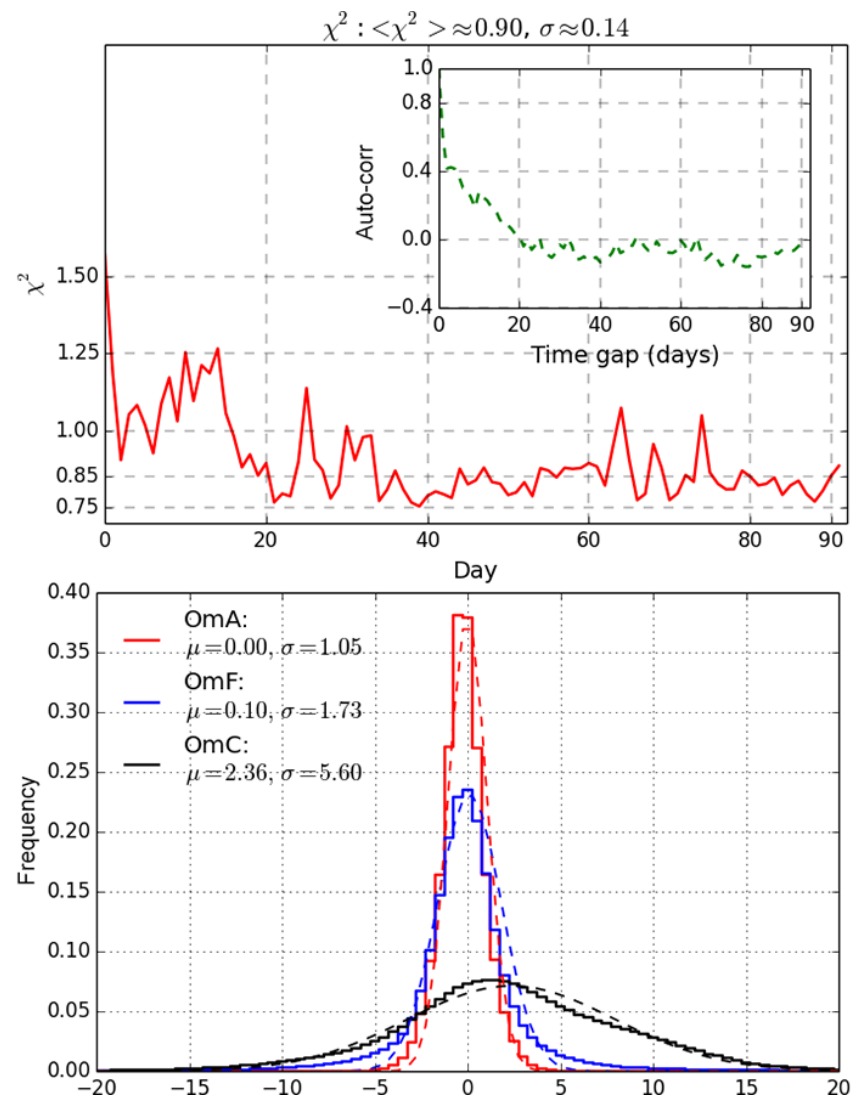

Figure 6. Self-consistency tests. Top panel: time series (red line) of $\chi^{2}$ for OmF and its associated autocorrelation signal (green line). For the $\chi^{2}$ diagnostic, we normalize the OmF differences by the background error. The labels show time in days ( $x$ axis) and $\chi^{2}$ value ( $y$ axis) for the $\chi^{2}$ plot and time gap in days ( $x$ axis) and autocorrelation ( $y$ axis) for the autocorrelation plot. Bottom panel: histograms of observations minus analysis (OmA - red solid line), observations minus forecast $(\mathrm{OmF}$ - blue solid line), and observations minus control run (OmC - black solid line). We normalize these differences by the observation error. The dashed lines correspond to the Gaussian fits of the different histograms. The labels show the OmA, OmF, or OmC differences ( $x$ axis) and the frequency of occurrence of the differences ( $y$ axis). We calculate the diagnostics OmA, OmF, and OmC over the period of 1 June-31 August 2003.
Figure 6 (top panel) shows the chi-squared time series for $\mathrm{OmF}$ and its associated autocorrelation function calculated over the 3-month period of the OSSE experiments, computed as daily averages. The chi-squared diagnostic starts with a maximum of about 1.56 and takes values down to 0.75 , with a mean of 0.9 over the OSSE 3-month period. The chi-squared time series is nearly stable since it exhibits relatively small variability (a standard deviation of about 0.14 ). Furthermore, the autocorrelation of the chi-squared statistic drops to zero, with no correlation after a time delay of 20 days. The calculation of the autocorrelation shows that the chi-squared statistic is uncorrelated after a time lag of 20 days; this means that after this time the mathematical expectation $E\left(\chi^{2}\right)$ is equal to the average of the chi-squared statistics. We find $E\left(\chi^{2}\right)=0.90$, which is close to the theoretical value of 1 (see Lahoz et al., 2007a). This result indicates that the a priori error statistics as represented in the $\mathbf{B}$ matrix slightly overestimate the actual error statistics from the OmF differences.

To test whether the observations, forecast, and analysis fields, as well as their associated errors, are consistent with each other, we calculate the histograms of OmA, OmF, and OmC only over land (normalized by the observation error) over the 3-month period (Fig. 6, bottom panel). For a properly set up assimilation system, the OmF and OmA normalized histograms should be close to a Gaussian distribution with mean of 0 and standard deviation of 1 . Figure 6 (bottom panel) shows that the OmA and OmF differences are close to a Gaussian distribution centered near to or at zero. The OmF has a mean and standard deviation of 0.10 and 1.73 , respectively, whereas the OmA has nearly a 0 mean and a standard deviation of 1.05. This indicates that the center of the OmA histogram is closer to zero and more peaked than the histogram of OmF. We expect this, since the analyses should be closer to the observations than the forecasts. Furthermore, the histogram for OmA indicates that the errors in the $\mathbf{R}$ matrix, the observational counterpart of the $\mathbf{B}$ matrix, are a good representation of the analysis error.

Based on the above results, we conclude that the background error covariance matrix, $\mathbf{B}$, and its observational counterpart, $\mathbf{R}$, prescribed in our assimilation system are reasonably well characterized (see, e.g., Lahoz et al., 2007a, for a discussion of the specification of errors in a data assimi- 
lation system). Furthermore, the above results are consistent with the assumption that the errors in the observations and the forecasts are Gaussian.

The shape of the OmC normalized histogram, which has a mean and standard deviation of 2.36 and 5.60, respectively, indicates the presence of a relatively large bias between the $\mathrm{S}-5 \mathrm{P}$ observations and the $\mathrm{CR}$. The assimilation reduces this bias, as shown by the analyses being significantly closer to the observations than the simulation from the CR. This shows that the assimilation of simulated S-5P CO total column observations has a significant impact on the $\mathrm{CO}$ forecasts and analyses.

\subsubsection{Study of increments}

To understand further the impact on the surface $\mathrm{CO}$ field of the simulated S-5P CO total column measurements, we calculate the analysis increment $(\delta x)$ for a single analysis time at 14:00 UTC on 15 June 2003. We calculate this increment as the analysis minus the model first guess ( $1 \mathrm{~h}$ forecast). The analysis increment provides a quantitative diagnostic of the quality of the analysis (see, e.g., Fitzmaurice and Bras, 2008).

Figure 7 (top panel) shows the spatial distribution of $\delta x$ at the model surface. One can see the spread of the impact of the simulated observations across large regions. This is due to S-5P having a wide swath allowing it to sample larger regions. The most substantial corrections are over land, where there are sufficient observations to have an impact. Over sea, the increments tend to be negligible, as any observations found there have relatively large errors. Thus, there will not be much difference between the model first guess and the analysis. Likewise, this is also true in the regions outside the satellite footprint.

To provide further insight into the impact of S-5P CO measurements, we calculate latitude-height and longitudeheight cross sections at $48.8^{\circ} \mathrm{N}, 2.6^{\circ} \mathrm{E}$, near Paris, for 15 June 2003. Figure 5 (bottom left and bottom right panels) shows a zoom of the zonal and meridional vertical slices of the analysis increment. We see significant corrections to the model first guess (identified by large increments) confined to a deep layer. These corrections are larger at the surface and exhibit a second maximum around $650 \mathrm{hPa}$. This vertical structure is mainly attributable to the forecast error standard deviation (given as a vertically varying fraction of the local $\mathrm{CO}$ mixing ratio), the square root of the diagonal entry of the $\mathbf{B}$ matrix, which is higher in the boundary layer (where the value of the S-5P CO averaging kernel is close to 1). The shape of the S-5P analysis increments also exhibits a second peak around $650 \mathrm{hPa}$. The increments for this particular day thus show a clear impact from the S-5P CO measurements in the PBL and the free troposphere.

The shape of the S-5P increments is similar to that of typical SCIAMACHY analysis increments, which also extend through a deep layer and have a maximum at the surface
(Tangborn et al., 2009). The fact that both these analysis increments stretch out over a deep layer is due to similarities in the S-5P and SCIAMACHY averaging kernels - both are close to unity over cloud-free land (see Fig. 5). Note that the situation shown in Fig. 7 is a snapshot and depends on the particular conditions for this time. An average of the increments over the summer period would tend to show a uniform distribution in height.

\subsection{Evaluation of the summer OSSE}

\subsubsection{Summer averages}

Figure 8 shows the fields of surface $\mathrm{CO}$ from the $\mathrm{CR}$, as well as the NR and the AR, averaged over the northern summer period. One can see the general change of $\mathrm{CO}$ over land between the CR (top left panel) and the AR (bottom panel). We can ascribe this to the contribution of simulated S-5P total column CO data sampled from the NR. This figure shows several differences between the CR and AR fields that indicate the superior behavior of the AR in capturing features in the NR. For example, over eastern Europe and Russia, the AR CO concentration values are closer to those in the NR (with a mean bias between -1.5 and +1.5 ppbv); in particular, the CR shows generally lower values than in the NR (mean bias around $-6 \mathrm{ppbv}$ ). Nevertheless, over Portugal, where the NR shows the forest fires that occurred over the summer, the AR captures them only slightly better than the $\mathrm{CR}$. We expect this relatively poor performance of the CR regarding fires, as the fires are not included in the CR setup (see Sect. 2.4). Although the AR, in the operational setup, captures the $\mathrm{CO}$ concentrations emitted by forest fires slightly better than the $\mathrm{CR}$ (through assimilation of $\mathrm{CO}$ measurements), the relatively poor temporal resolution of the S-5P ultimately limits its performance. However, the most important deficiency is due to the criterion used in the operational setup in which we activate a data-screening test to discard observations far away from the model (see Sect. 3.2.5). A geostationary satellite, given its relatively high temporal resolution, should be able to capture better the temporal variability of CO from these forest fires (Edwards et al., 2009).

\subsubsection{Statistical metrics}

In this section, we provide a quantitative assessment of the benefit from S-5P CO total column measurements on the CO surface analysis. For this, we perform a statistical analysis of the different OSSE experiments for northern summer 2003.

We calculate the mean bias (MB, in parts per billion by volume, ppbv), its magnitude reduction (MBMR, ppbv), and the root mean square error (RMSE, ppbv) and its reduction rate (RMSERR, \%). Note that although recent papers have raised concerns over the use of the RMSE metric (Willmott and Matsuura, 2005; Willmott et al., 2009), Chai and Draxler (2014) discuss circumstances where the RMSE is 

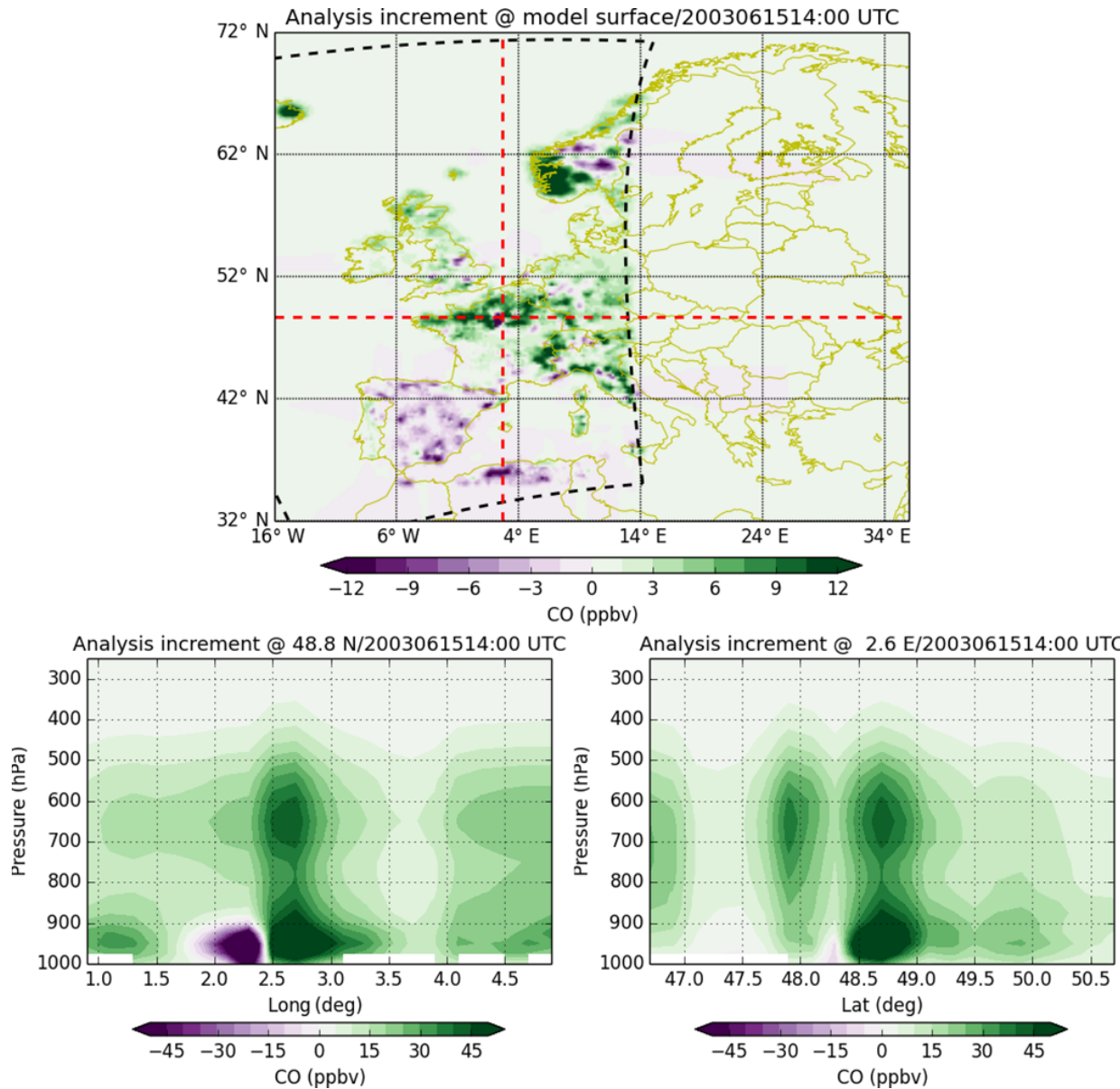

Figure 7. S-5P CO analysis increments, units of ppbv, at 14:00 UTC on 15 June 2003. Top panel: geographical distribution at the model surface. Red dashed lines show zonal and meridional vertical slices at $48^{\circ} 8^{\prime} \mathrm{N}$ and $2^{\circ} 6^{\prime} \mathrm{E}$, respectively. The black dashed line shows the S-5P cross-track at 13:12 UTC, clipped to fit the OSSE simulation domain. Note that we measure the S-5P CO observations at 13:12 UTC. The labels show longitude in degrees ( $x$ axis) and latitude in degrees ( $y$ axis). Left and right bottom panels show, respectively, the longitudeheight and latitude-height cross sections at a location near Paris. The labels for the bottom panels show longitude in degrees $(x$ axis, left panel), latitude in degrees ( $x$ axis, right panel), and pressure in $\mathrm{hPa}$ ( $y$ axis, both panels). Green/purple colors indicate positive/negative values in the increment fields.

more beneficial. We use the correlation coefficient, $\rho$, to measure the linear dependence between two datasets and the fraction of the true variability (i.e., variability represented by the $\mathrm{NR}$ ) reproduced by the $\mathrm{CR}$ or $\mathrm{AR}$.

For a single model grid box, we define the statistical metrics (MB, RMSE, $\rho$ ) with respect to the NR as

$$
\begin{aligned}
& \operatorname{MBMR}=|\mathrm{MB}(\mathrm{CR})|-|\mathrm{MB}(\mathrm{AR})| \\
& \operatorname{RMSE}(X)=\sqrt{\frac{1}{N} \sum(X-\mathrm{NR})^{2}} \\
& \operatorname{RMSERR}=100 \times\left(1-\frac{\mathrm{RMSE}(\mathrm{AR})}{\mathrm{RMSE}(\mathrm{CR})}\right) \\
& \rho(x)=\frac{\sum(X-\bar{X})(\mathrm{NR}-\mathrm{NR})}{\sqrt{\sum(X-\bar{X})^{2} \sum(\mathrm{NR}-\mathrm{NR})^{2}}}
\end{aligned}
$$

where $X$ denotes the $\mathrm{CR}$ or the $\mathrm{AR} ; N$ is the number of data samples, the vertical bars denote the absolute value operator, and the overbar symbol represents the arithmetic mean operator. The MB metric gives the average value by which the $\mathrm{CR}$ or the AR differs from the NR over the entire dataset.

\subsubsection{Results of the statistical tests}

Figure 9 presents the zonal and meridional means of the difference between the CR and the AR averaged over the northern summer 2003 (1 June-31 August). We also plot the confidence interval representing the areas where the AR is not significantly different to the CR at the $99 \%$ confidence limit (highlighted in grey). These two figures show that there is benefit from the S-5P CO total column data over the first few bottom levels of the troposphere, i.e., the lowermost troposphere. Between the surface and $800 \mathrm{hPa}$, a negative peak is 

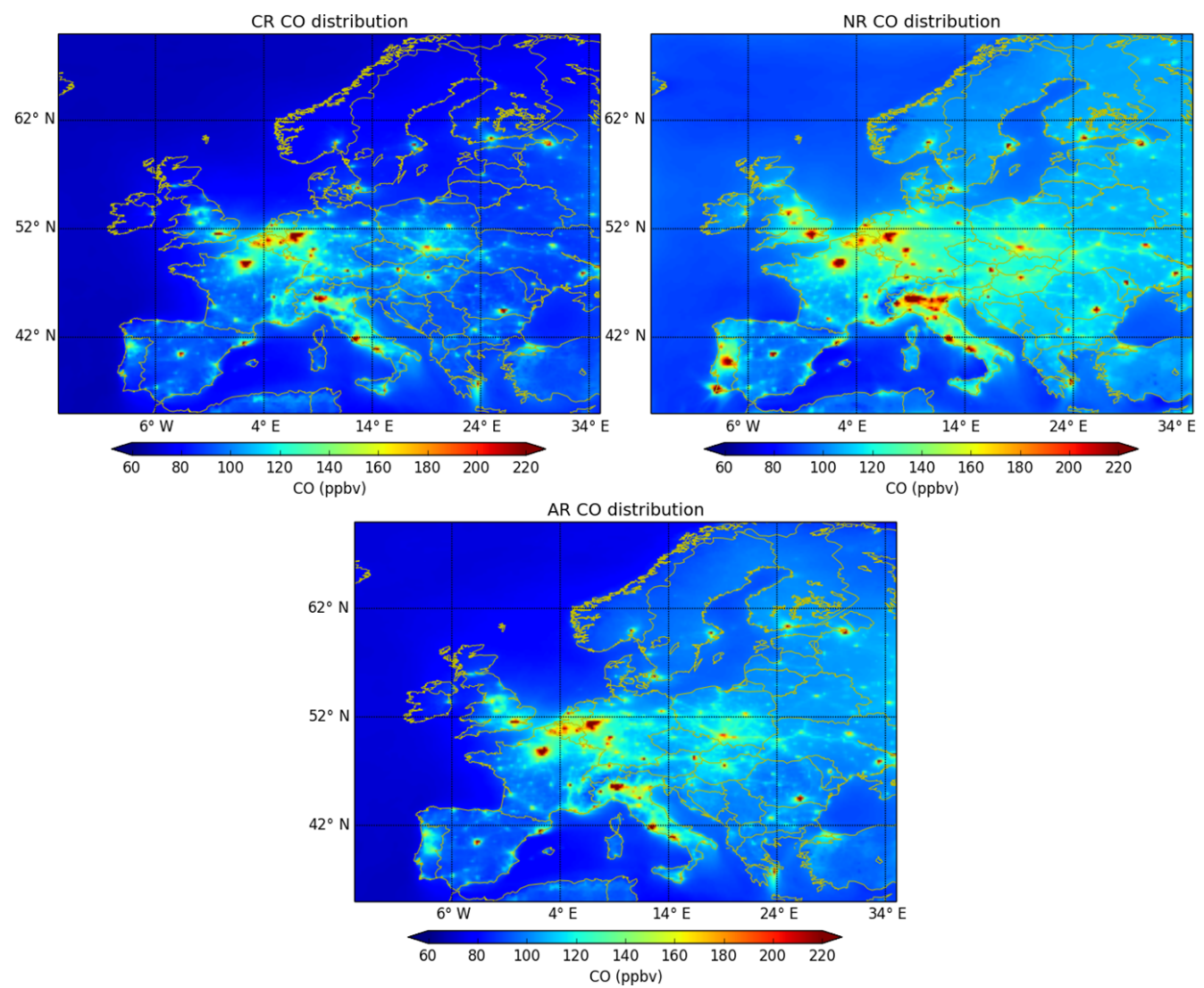

Figure 8. Distribution of CO surface concentrations, units of ppbv, averaged for the period 1 June-31 August 2003. Top left panel: the control run (CR) from MOCAGE; right top panel: the nature run (NR) from LOTOS-EUROS; bottom panel: the assimilation run (AR) from MOCAGE obtained after assimilating the S-5P CO total column simulated data sampled from the NR. In all panels, the labels show longitude in degrees ( $x$ axis) and latitude in degrees ( $y$ axis). Red/blue colors indicate relatively high/low values of the CO surface concentrations.


Figure 9. Zonal (left panel) and meridional (right panel) slices of the difference between the CR and AR CO fields, units of ppbv, averaged over the summer period (1 June-31 August 2003). The areas highlighted in grey color indicate where the AR is not significantly different to the $\mathrm{CR}$ at the $99 \%$ confidence level. The labels in the left panel are latitude in degrees ( $x$ axis) and pressure in hPa ( $y$ axis). The labels in the right panel are longitude in degrees ( $x$ axis) and pressure in $\mathrm{hPa}(y$ axis). Green/purple colors indicate positive/negative values in the difference fields.

present in the zonal difference field (over Scandinavia) and in the meridional difference field (over eastern Europe). Note that the zonal field shows two areas, one with positive values and the other with negative values, representing a CR greater than the AR and a CR smaller than the AR, respectively. The positive peak, at a slightly higher level (i.e., lower pressure) than the negative peak, is representative of the Mediterranean Sea, whereas the negative peak is more representative of the land areas (Scandinavia and eastern Europe). Figure 9 indicates that the S-5P CO corrects the model in the lower tro- 
posphere with a larger impact over land and with a smaller impact in the PBL. This is consistent with the behavior of the analysis increments shown in Fig. 7.

Figure 10 shows the performance of the biases between the CR and the NR, and the AR and the NR at the surface, as well as averaged over the northern summer of 2003 (1 June31 August). The MBMR, which compares the magnitude of the CR vs. NR and AR vs. NR biases, indicates the geographical areas where the simulated S-5P CO total column data have the most impact. The MBMR shows that the AR is closer to the NR than the CR, almost everywhere in the domain (reflected by the prevalence of the red colors in the bottom left panel). This indicates that the simulated S-5P CO total column data generally provide a benefit at the surface, and especially over land areas where the $\mathrm{CO}$ sources are sparse. This suggests that due to the relatively small variability of $\mathrm{CO}$ over remote land regions, the S-5P data can provide a larger benefit compared to regions where the variability is relatively high.

We also calculate the RMSE as well as the reduction rate of the RMSE, RMSERR (Fig. 11), both keeping the systematic error (Fig. 11, top) and removing the systematic error (Fig. 11, bottom). We calculate the bias in the AR and CR by subtracting the NR field from each of them, producing an unbiased AR and CR. For the case where we remove the systematic error, we perform the statistics on the unbiased AR and CR. If we examine the RMSE statistics, Fig. 9 shows that the CR gets closer to the NR over the Atlantic Ocean and over the eastern domain, including Russia and Scandinavia, when we remove the systematic error. For example, over these areas we obtain $\sim 30 \mathrm{ppbv}$ and $\sim 10 \mathrm{ppbv}$ for the RMSE keeping and removing the systematic error, respectively. For the reduction of the RMSE, RMSERR, the behavior for the CR is similar overall, showing a reduction rate of $60 \%$ and 30-45\% keeping and removing the systematic error, respectively. Note that over Scandinavia the reduction rate goes down from $60 \%$ to about $10 \%$ after removing the systematic error.

These results indicate that S-5P CO data show more benefit when keeping the systematic error in the calculation of the RMSE. Following our guiding principle of avoiding an overoptimistic OSSE, we consider only the values of RMSE obtained when we remove the systematic error. For this case, the average reduction rate for the AR is around $20-25 \%$ over land (except Scandinavia) and close to $10 \%$ over sea and over Scandinavia.

In Fig. 12, we show the correlation between the CR and the $\mathrm{NR}$, as well as the correlation between the AR and the NR, at the surface for the 3 northern summer months (1 June31 August). The AR is closer than the CR to the NR with the correlation coefficient reaching 0.9 over land. By contrast, the correlation coefficient between the CR and the NR is typically less than 0.5 , with very low values over eastern Europe, where CO sources are sparse.

\subsubsection{Time series at selected locations}

Figure 13 shows time series from the NR, the CR, and the AR over the three areas of the study domain represented by the squares shown in Figs. 10 (bottom panel) and 11 (right panels): (i) the Paris region (Fig. 13, top panel); (ii) a region over Portugal $\left(5^{\circ} \mathrm{W}-40^{\circ} \mathrm{N}\right)$, where forest fires occur during the northern summer (Fig. 13, middle panel); and (iii) an area in the eastern part of the study domain $\left(25^{\circ} \mathrm{E}-53^{\circ} \mathrm{N}\right)$, where the reduction of RMSE (i.e., RMSERR) is much larger than for other regions (Fig. 13, bottom panel). For all three areas, the AR is generally closer to the NR than the CR, showing the impact of the simulated observations. We calculate the biases between the AR and CR vs. the NR by computing the difference NR- $X$, where $X$ is AR or CR, and normalizing by the number of observations over the northern summer period. The biases are (i) $48 \mathrm{ppbv}$ for $\mathrm{CR}$ and $38 \mathrm{ppbv}$ for $\mathrm{AR}$ in the Paris region, (ii) $101 \mathrm{ppbv}$ for $\mathrm{CR}$ and $83 \mathrm{ppbv}$ for $\mathrm{AR}$ in Portugal, and (iii) $21 \mathrm{ppbv}$ for $\mathrm{CR}$ and $5 \mathrm{ppbv}$ for AR in the eastern part of domain. Note that the AR and the CR capture the variability but not the values of the peaks. However, the LEO only samples at most twice a day over Paris and may not capture the peaks. In Fig. 13, we indicate the S-5P revisit time by the plus signs at the top of the panel and one can see that the peaks do not coincide with the time of the S-5P measurements. Another factor could also be that the emission inventory used in the AR has lower values than the one used in the NR.

Over Paris (top panel), the CR is already close to the NR and the impact of the S-5P CO simulated observations is small. Over Portugal (middle panel), the presence of fires is not seen in the CR (e.g., a maximum of $\mathrm{CO}$ at the beginning of the heat wave), as the fire emissions were not taken into account in the CR as they are not known a priori (see Sect. 2.4). In contrast, over this specific location we see the impact of the fires on the CO concentrations in the AR with, however, much lower values than for the NR. During the fires, the CO concentrations in the AR over Portugal are larger than $500 \mathrm{ppbv}$, whereas the CR remains relatively unchanged with concentrations less than 200 ppbv. Over the eastern part, where there are lower emissions compared for instance to Paris (bottom panel), the temporal variability is not high and the magnitude of the bias between the CR and the NR is small, but it is removed in the AR. Moreover, note that the operational screening test was still in force (see section below).

\subsubsection{Sensitivity tests for fire episode}

The assimilation system we use has a default criterion to discard CO column observations with values larger than $75 \%$ of the MOCAGE value. This criterion is not appropriate to situations resulting in excessive values in the $\mathrm{CO}$ concentrations, as is the case for forest fires. To understand further the performance of the OSSE over the period of the Portugal forest 

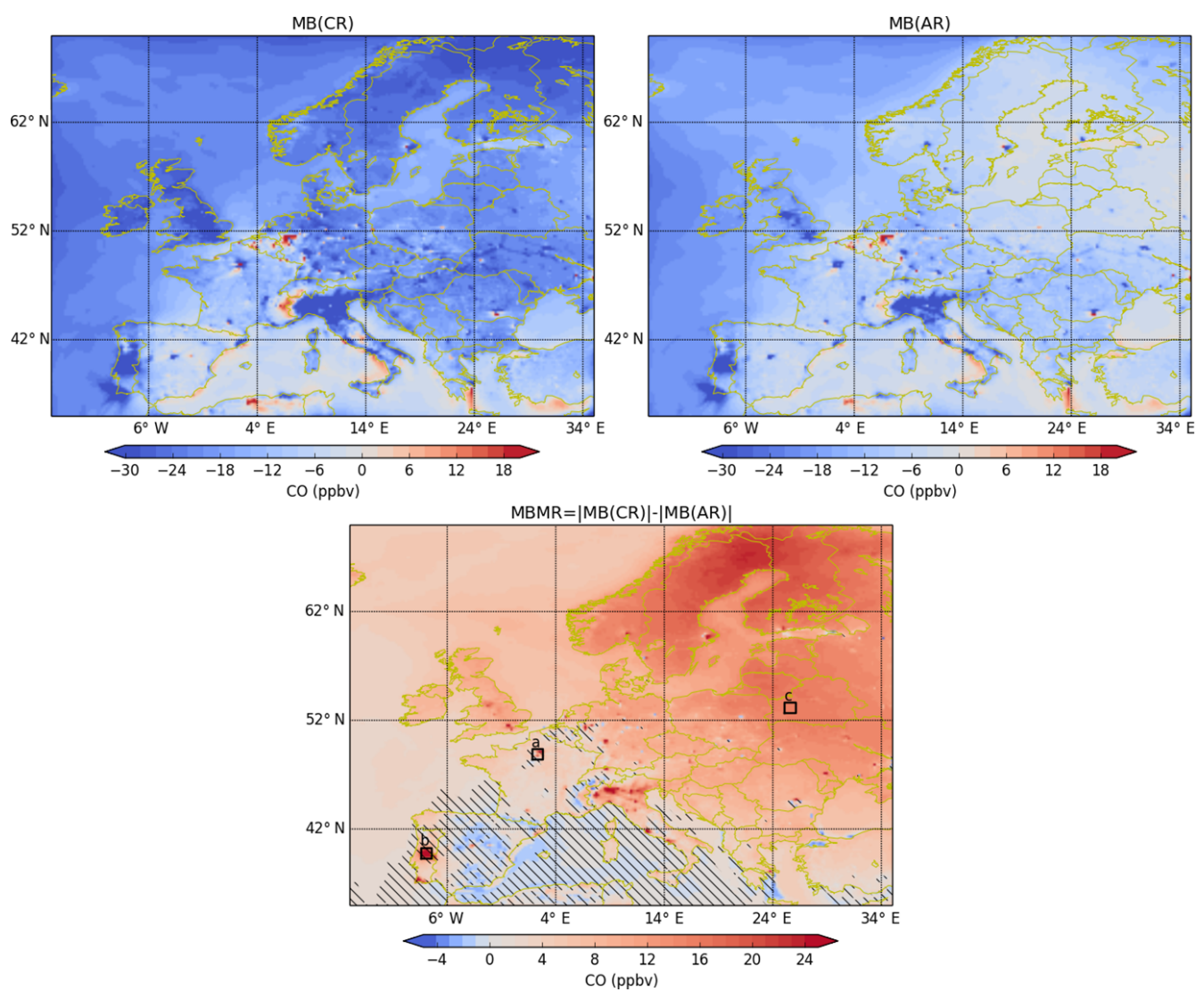

Figure 10. Mean bias reduction at the surface for CO, units of ppbv: Left top panel shows the CR mean bias with respect to the NR (CRNR). Right top panel shows the AR mean bias with respect to the NR (AR-NR). Bottom panel shows the mean bias magnitude reduction (absolute value of the mean bias for CR minus the absolute value of the mean bias for AR). We average the data over northern summer 2003 (1 June-31 August). The labels show longitude in degrees ( $x$ axis) and latitude in degrees ( $y$ axis). The hatched area in the bottom panel shows where the mean bias plotted in this panel (MBMR) is not statistically significant at the $99 \%$ confidence level. The three squares in the bottom panel represent the locations for the three time series shown in Fig. 13. Red/blue colors indicate positive/negative values in the MB/MBMR.

fires we perform a second OSSE without this default criterion. This second OSSE covers the period of the forest fires (25 July-15 August). For this second OSSE, we compare the total column values and the surface values of the $\mathrm{CO}$ fields from the CR and the AR (Figs. 14 and 15, respectively).

Figure 14 shows the CO total column at 14:15 UTC on 4 August 2003 (during the period of the Portugal forest fires) from the NR (top left panel), the simulated S-5P observations (top right panel), the CR (bottom left panel), and the AR (bottom right panel). We can see that the AR captures the fire event, indicated by relatively high values of the $\mathrm{CO}$ total column over Portugal, whereas the CR does not. This confirms the results shown in Fig. 13, which highlight the benefit provided by the S-5P CO total column measurements, in particular regarding the capture of the signature of the Portugal forest fires. Note that the S-5P measurement is noisedominated over the sea (top right panel). This accounts for the sharp edge in the CO total column field seen between the
Iberian Peninsula and the Bay of Biscay for the AR (bottom right panel).

Figure 15 shows the time series of the surface $\mathrm{CO}$ concentrations over the period 25 July-15 August (that of the Portugal forest fires). In comparison to the original OSSE (see middle panel of Fig. 13), the AR is now closer to the NR, having now peak values of about $900 \mathrm{ppbv}$ instead of peak values of about 550 ppbv. The CR still has peak values less than 200 ppbv. This indicates that the relatively low values in the AR (in comparison to the NR) for the original OSSE shown in the middle panel of Fig. 13 result from the application of the default criterion to discard CO column observations that are far away from MOCAGE values. The results from Fig. 15 confirm those shown in Fig. 14 and reinforce the benefit provided by the S-5P CO total column measurements, in particular regarding the capture of the signature of the Portugal forest fires. This sensitivity test also shows the limitations of using standard operational criteria. 

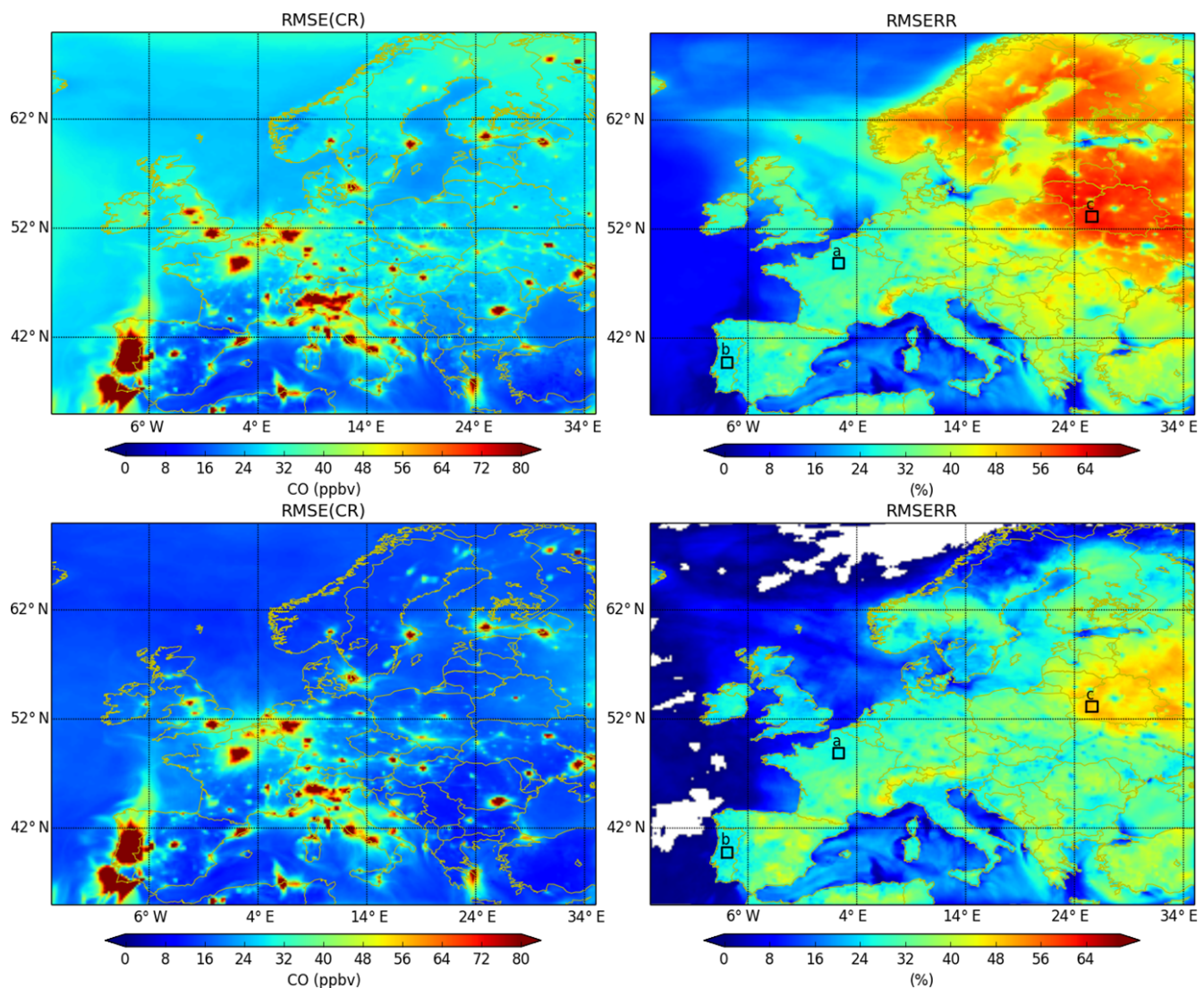

Figure 11. Top: root mean square error (RMSE), units of ppbv, between CR and NR (left panel), and its corresponding reduction rate RMSERR in \% (right panel), keeping the systematic error. Bottom: same as top panel but calculating the RMSE after removing the systematic error. The labels on each panel are longitude in degrees ( $x$ axis) and latitude in degrees ( $y$ axis). The three squares in the two right panels represent the locations for the three time series shown in Fig. 13. Red/blue colors indicate relatively high/low values in the RMSE/RMSERR.
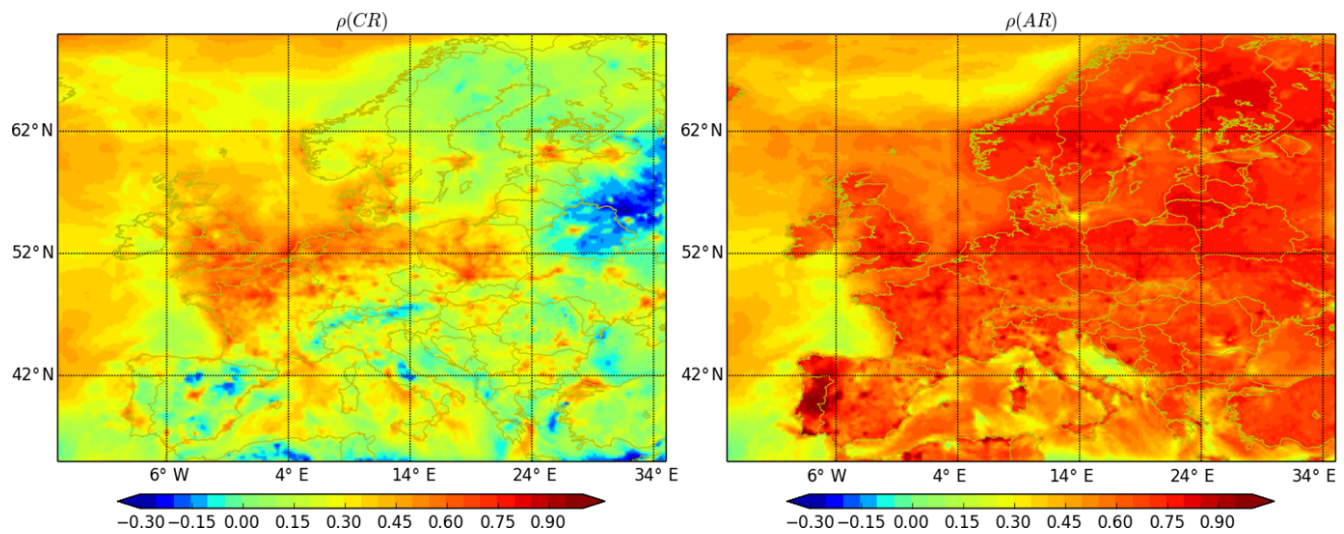

Figure 12. Correlation coefficient between the CR and the NR (left panel) and the AR and the NR (right panel) at the surface and for the northern summer period (1 June-31 August). The labels are longitude in degrees ( $x$ axis) and latitude in degrees ( $y$ axis). Red/blue colors indicate positive/negative values of the correlation coefficient.

\section{Conclusions}

We perform a regional-scale OSSE over Europe to explore the impact of the LEO satellite mission S-5P CO total column measurements on lowermost tropospheric air pollution analyses, with a focus on CO surface concentrations and the PBL. The PBL varies in depth throughout the year but is contained within the lowermost troposphere (heights $0-3 \mathrm{~km}$ ) and typ- 


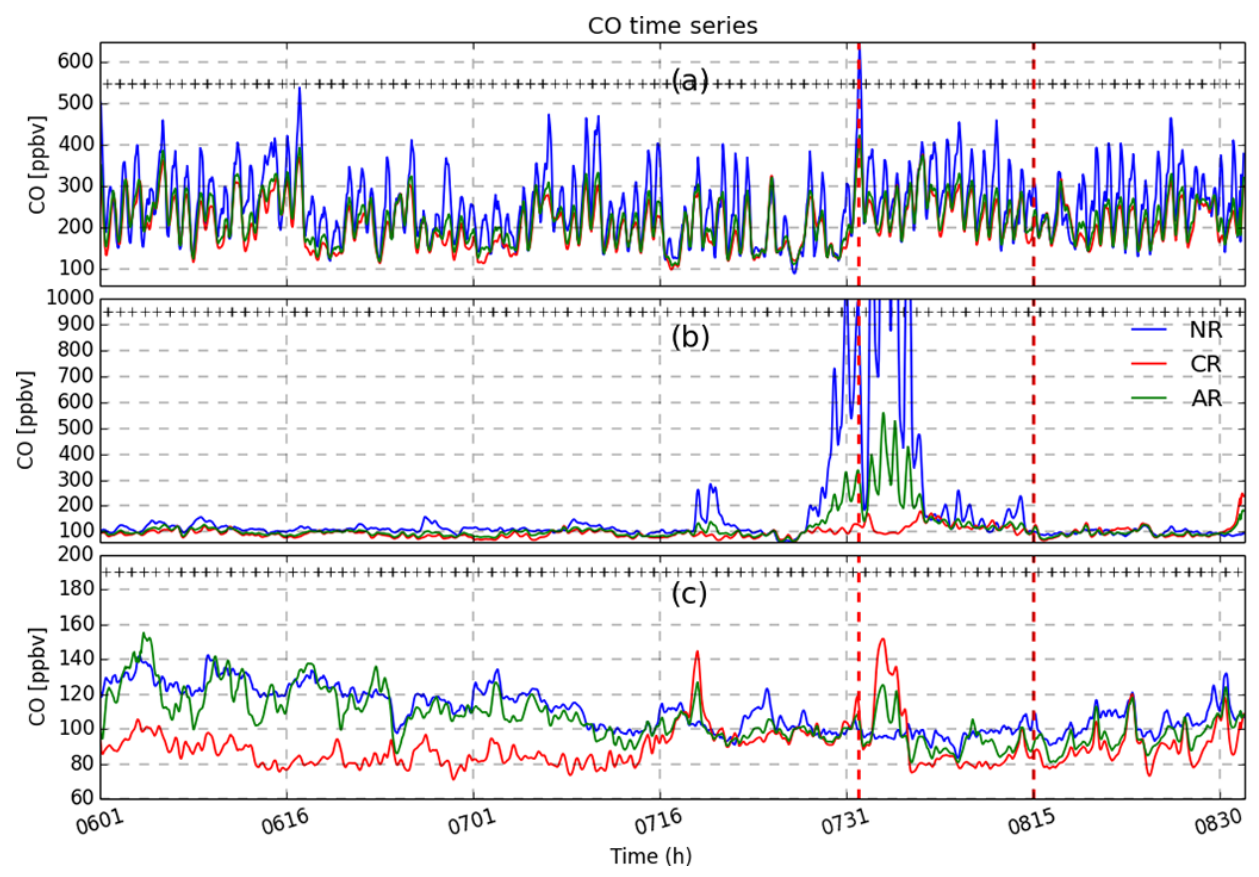

Figure 13. Time series for CO surface concentrations (1 June-31 August) from NR (blue color), CR (red color), and AR (green color) over three different locations represented by squares in Figs. 10 and 11. Top panel: area near Paris; middle panel: area over Portugal, where forest fires occurred; bottom panel: eastern part of the study domain. The labels in the three panels are time in format MMDD ( $x$ axis) and CO concentration in ppbv ( $y$ axis). The plus symbols at the top of each panel indicate availability of observations from the S-5P platform.

ically spans the heights $0-1 \mathrm{~km}$. We focus on northern summer 2003, which experienced a severe heat wave with severe societal impact over Europe.

Our guiding principle in the setup of this OSSE study is to avoid overoptimistic results. To achieve this, we address several factors considered likely to contribute to an overoptimistic OSSE. (i) We use different models for the NR and the OSSE experiments. (ii) We check that the differences between the NR and actual measurements of $\mathrm{CO}$ are comparable to the $\mathrm{CO}$ field differences between the model used for the OSSE and the NR. (iii) We remove the systematic error (calculated as the bias against the NR) in the OSSE outputs (AR and CR) and compare the unbiased results to the NR. (iv) We perform a quantitative evaluation of the OSSE results, including performing statistical significance tests and self-consistency and chi-squared tests. Based on the specifications of the TROPOMI instrument, we anticipate relatively low CO column uncertainties of around $5 \%$ over the European continent. Finally, our approach was to study the performance of S-5P alone without taking into account other existing or future missions (i.e., MOPITT, CrIS, or IASI).

The OSSE results indicate that simulated S-5P CO total column measurements during northern summer 2003 benefit efforts to monitor surface $\mathrm{CO}$. The largest benefit occurs over land in remote regions (eastern Europe, including Russia) where CO sources are sparse. Over these land areas, and for the case when we remove the systematic error, we ob- tain a lower RMSE value (by $\sim 10 \mathrm{ppbv}$ ) for the AR than for the CR, in both cases vs. the NR. Over sea and Scandinavia, we also obtain a lower RMSE (by $\sim 10 \%$ ) for the AR than for the CR, in both cases vs. the NR. Consistent with this behavior, we find the AR is generally closer to the NR than the $\mathrm{CR}$ to the NR, with a correlation coefficient reaching 0.9 over land (NR vs. AR). By contrast, the correlation coefficient between the CR and the NR is typically less than 0.5 , with very low values over eastern Europe, where $\mathrm{CO}$ sources are sparse. In general, for all the metrics calculated in this paper, there is an overall benefit over land from the S-5P CO total column measurements in the free troposphere as well as at the surface. Significance tests on the CR and AR results indicate that, generally, the differences in their performance are significant at the $99 \%$ confidence level. This indicates that the S-5P CO total column measurements provide a significant benefit to monitor surface $\mathrm{CO}$.

We further show that, locally, the AR is capable of reproducing the peak in the $\mathrm{CO}$ distribution at the surface due to forest fires (albeit, weaker than the NR signal), even if the $\mathrm{CR}$ does not have the signature of the fires in its emission inventory. A second OSSE shows that this relatively weak signal of the forest fires in the AR arises from the use of a default criterion to discard $\mathrm{CO}$ total column observations too far from model values, a criterion not appropriate to situations resulting in excessive values in the $\mathrm{CO}$ concentrations, as is the case for forest fires. This second OSSE shows a 
Fire event over Portugal: 20030804 14:15 UTC
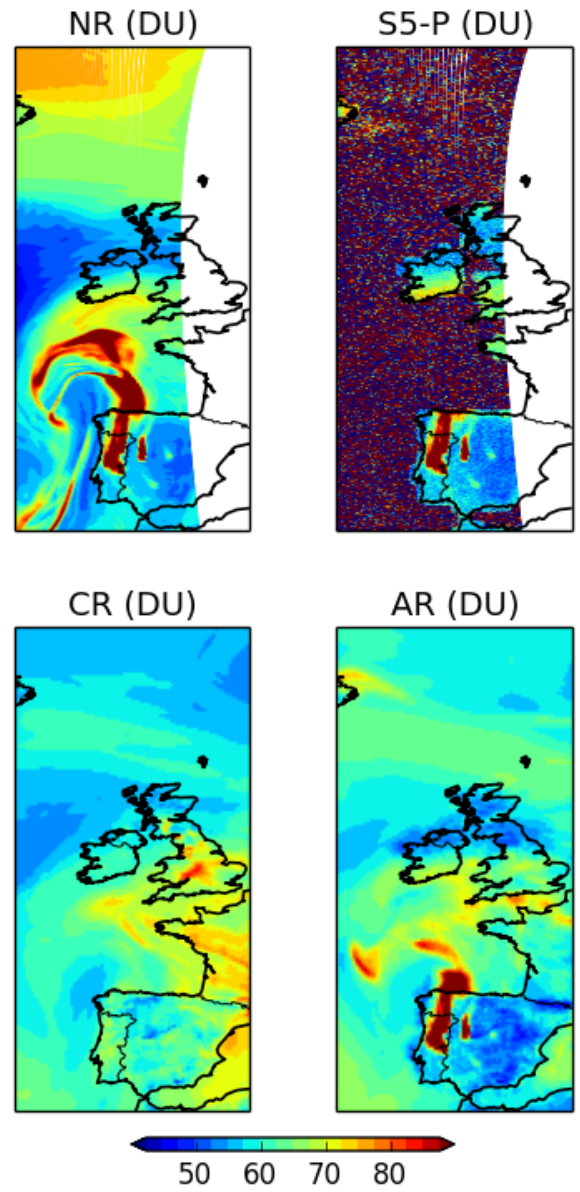

$1 \mathrm{DU}=2.685 \times 10^{16}$ molecules $\mathrm{cm}^{2}$

Figure 14. CO total column at 14:15 UTC on 4 August 2003. DU indicates Dobson units. Top left panel: NR; top right panel: simulated S-5P observations; bottom left panel: CR; bottom right panel: AR. Red/blue colors indicate relatively high/low values of the $\mathrm{CO}$ total column.

much stronger signal in the AR, which is now much closer to the NR than the CR, confirming the benefit of S-5P CO total column measurements and the limitations of using standard operational criteria in this case.

Further work will involve extending the OSSE approach to other S-5P measurements, such as ozone total column, and $\mathrm{NO}_{2}$ and formaldehyde tropospheric columns. These studies will complement similar studies on the benefit from S4 and S-5 measurements. Collectively, these OSSE studies will provide insight into the relative benefits from the S-4, S5 and S-5P platforms for monitoring atmospheric pollution processes.

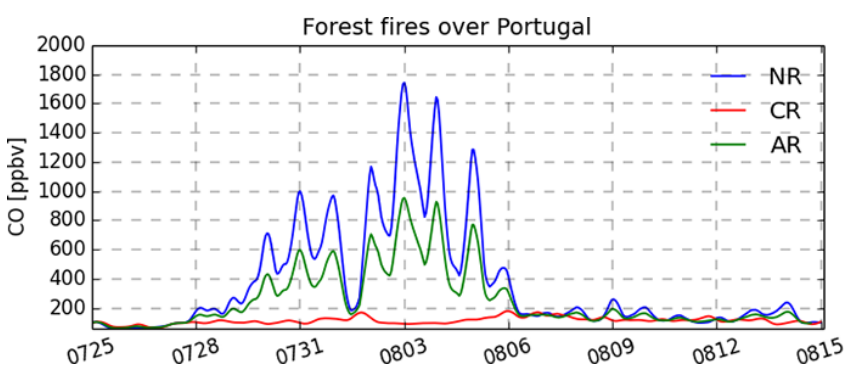

Figure 15. Time series for $\mathrm{CO}$ surface concentrations for the period covering the Portugal forest fires (25 July-15 August) from NR (blue color), CR (red color), and AR (green color) over the location associated with the middle panel of Fig. 13. These data concern the second OSSE we perform to understand the behavior of the original OSSE over the period of the forest fires (see text for more details). The labels are time, in format MMDD ( $x$ axis), and CO concentration, in ppbv ( $y$ axis).

Acknowledgements. Support for this work came partly from the ESA funded project "Impact of Spaceborne Observations on Tropospheric Composition Analysis and Forecast" (ISOTROP-ESA contract number 4000105743/11/NL/AF). W. Lahoz acknowledges support from an internal project from NILU. R. Abida, J.-L. Attié, P. Ricaud, L. El Amraoui, and W. Lahoz acknowledge support from the RTRA/STAE. J. Kujanpää and J. Tamminen acknowledge support from the Academy of Finland (project no. 267442).

Edited by: Q. Errera

Reviewed by: J. Warner and two anonymous referees

\section{References}

Acarreta, J. R., De Haan, J. F., and Stammes P.: Cloud pressure retrieval using the $\mathrm{O} 2-\mathrm{O} 2$ absorption band at $477 \mathrm{~nm}$, J. Geophys. Res., 109, D05204, doi:10.1029/2003JD003915, 2004.

Arnold Jr., C. P. and Dey, C. H.: Observing-systems simulation experiments: Past, present and future, B. Am. Meteorol. Soc., 67, 687-695, 1986.

Atlas, R.: Atmospheric observation and experiments to assess their usefulness in data assimilation, J. Meteor. Soc. Jpn., 75, 111130, 1997.

Atlas, R., Emmitt, G. D., Brin, T. E., Ardizzone, J., Jusem, J. C., and Bungato D.: Recent observing system simulation experiments at the NASA DAO, in: Preprints, 7th Symposium on Integrated Observing Systems, Long Beach, CA: American Meteorological Society, 2003.

Bannister, R. N.: A review of forecast error covariance statistics in atmospheric variational data assimilation. I: characteristics and measurements of forecast error covariances, Q. J. Roy. Meteor. Soc., 134, 1951-1970, doi:10.1002/qj.339, 2008.

Barbosa, P., San-Miguel-Ayanz, J., Camia, A., Gimeno, M., Liberta, G., and Schmuck, G.: Assessment of fire damages in the EU Mediterranean Countries during the 2003 Forest Fire Campaign. Official Publication of the European Commission, S.P.I.04.64, Joint Research Center, Ispra, 2004. 
Barré, J., Edwards, D., Worden, H., Da Silva, A., and Lahoz, W.: On the feasibility of monitoring air quality in the lower troposphere from a constellation of northern hemisphere geostationary satellites (Part 1). Atmos. Environ., 113, 63-77, doi:10.1016/j.atmosenv.2015.04.069, 2015.

Bencherif, H., El Amraoui, L., Semane, N., Massart, S., Vidyaranya, D. C., Hauchecorne, A., and Peuch, V.-H.: Examination of the 2002 major warming in the southern hemisphere using ground-based and Odin/SMR assimilated data: stratospheric ozone distributions and tropic/mid-latitude exchange, Can. J. Phys., 85, 1287-1300, 2007.

Bousserez, N., Attié, J. L., Peuch, V.-H., Michou, M., Pfister, G., Edwards, D., Emmons, L., Mari, C., Barret, B., Arnold, S. R., Heckel, A., Richter, A., Schlager, H., Lewis, A., Avery, M., Sachse, G., Browell, E. V., and Hair, J. W.: Evaluation of the MOCAGE chemistry transport model during the ICARTT/ITOP experiment, J. Geophys. Res., 112, D10S42, doi:10.1029/2006JD007595, 2007.

Buchwitz, M., de Beek, R., Noël, S., Burrows, J. P., Bovensmann, H., Schneising, O., Khlystova, I., Bruns, M., Bremer, H., Bergamaschi, P., Körner, S., and Heimann, M.: Atmospheric carbon gases retrieved from SCIAMACHY by WFM-DOAS: version $0.5 \mathrm{CO}$ and $\mathrm{CH}_{4}$ and impact of calibration improvements on $\mathrm{CO}_{2}$ retrieval, Atmos. Chem. Phys., 6, 2727-2751, doi:10.5194/acp6-2727-2006, 2006.

Chai, T. and Draxler, R. R.: Root mean square error (RMSE) or mean absolute error (MAE)? - Arguments against avoiding RMSE in the literature, Geosci. Model Dev., 7, 1247-1250, doi:10.5194/gmd-7-1247-2014, 2014.

Claeyman, M., Attié, J.-L., Peuch, V.-H., El Amraoui, L., Lahoz, W. A., Josse, B., Joly, M., Barré, J., Ricaud, P., Massart, S., Piacentini, A., von Clarmann, T., Höpfner, M., Orphal, J., Flaud, J.M., and Edwards, D. P.: A thermal infrared instrument onboard a geostationary platform for $\mathrm{CO}$ and $\mathrm{O}_{3}$ measurements in the lowermost troposphere: Observing System Simulation Experiments (OSSE), Atmos. Meas. Tech., 4, 1637-1661, doi:10.5194/amt-41637-2011, 2011.

Courtier, P., Freydier, C., Geleyn, J., Rabier, F., and Rochas, M.: The ARPEGE project at Météo France, in: Atmospheric Models, vol. 2, 193-231, Workshop on Numerical Methods, Reading, UK, 1991.

Curier, R. L., Timmermans, R., Calabretta-Jongen, S., Eskes, H., Segers, A., Swart, D., and Schaap, M.: Improving ozone forecasts over Europe by synergistic use of the LOTOS-EUROS chemical transport model and in-situ measurements, Atmos. Environ., 60, 217-226, doi:10.1016/j.atmosenv.2012.06.017, 2012.

Cuvelier, C., Thunis, P., Vautard, R., Amann, M., Bessagnet B., Bedogni, M., Berkowicz, R., Brandt, J., Brocheton, F., Builtjes, P., Coppalle, A., Denby, B. Douros, G., Graf, A., Hellmuth, O., Honoré, C., Hodzic, A., Jonson, J., Kerschbaumer, A., de Leeuw, F., Minguzzi, E., Moussiopoulos, N., Pertot, C., Pirovano, G., Rouil, L., Schaap, M., Stern, R., Tarrason, L., Vignati, E., Volta, M., White, L., Wind, P., and Zuber, A.: CityDelta: A model intercomparison study to explore the impact of emission reductions in European cities in 2010, Atmos. Environ., 41, 189-207, doi:10.1016/j.atmosenv.2006.07.036, 2007.

de Haan, J. F.: DISAMAR Algorithms and background, RPTROPOMI-KNMI-066, KNMI, January 2012.
Dufour, A., Amodei, M., Ancellet, G., and Peuch, V. H.: Observed and modeled "chemical weather" during ESCOMPTE, Atmos. Res., 74, 161-189, 2004.

Edwards, D. P., Emmons, L. K., Hauglustaine, D. A., Chu, A., Gille, J. C., Kaufman, Y. J., Pétron, G., Yurganov, L. N., Giglio, L., Deeter, M. N., Yudin, V., Ziskin, D. C., Warner, J., Lamarque, J.F., Francis, G. L., Ho, S. P., Mao, D., Chan, J., and Drummond, J. R.: Observations of Carbon Monoxide and Aerosol From the Terra Satellite: Northern Hemisphere Variability, J. Geophys. Res., 109, D24202, doi:10.1029/2004JD004727, 2004.

Edwards, D. P., Emmons, L. K., Gille, J. C., Chu, A., Attié, J.-L., Giglio, L., Wood, S. W., Haywood, J., Deeter, M. N., Massie, S. T., Ziskin, D. C., and Drummond, J. R.: Satellite Observed Pollution From Southern Hemisphere Biomass Burning, J. Geophys. Res., 111, D14312, doi:10.1029/2005JD006655, 2006.

Edwards, D. P., Arellano Jr., A. F. and Deeter, M. N.: A satellite observation system simulation experiment for carbon monoxide in the lowermost troposphere, J. Geophys. Res., 114, D14304, doi:10.1029/2008JD011375, 2009.

El Amraoui, L., Peuch, V.-H., Ricaud, P., Massart, S., Semane, N., Teyssèdre, H., Cariolle, D., and Karcher, F.: Ozone loss in the 2002/03 Arctic vortex deduced from the Assimilation of Odin/SMR $\mathrm{O}_{3}$ and $\mathrm{N}_{2} \mathrm{O}$ measurements: $\mathrm{N}_{2} \mathrm{O}$ as a dynamical tracer, Q. J. Roy. Meteor. Soc., 134, 217-228, 2008a.

El Amraoui, L., Semane, N., Peuch, V.-H., and Santee, M. L.: Investigation of dynamical processes in the polar stratospheric vortex during the unusually cold winter 2004/2005, Geophys. Res. Lett., 35, L03803, doi:10.1029/2007GL031251, 2008b.

Elbern, H., Strunk, A., and Nieradzik, L.: "Inverse modelling and combined state-source estimation for chemical weather," in: Data Assimilation: Making Sense of Observations, edited by: Lahoz, W. A., Khattatov, B., and Ménard, R., Springer, Berlin, 491-513, 2010.

Emili, E., Barret, B., Massart, S., Le Flochmoen, E., Piacentini, A., El Amraoui, L., Pannekoucke, O., and Cariolle, D.: Combined assimilation of IASI and MLS observations to constrain tropospheric and stratospheric ozone in a global chemical transport model, Atmos. Chem. Phys., 14, 177-198, doi:10.5194/acp-14177-2014, 2014.

Fitzmaurice, J. and Bras, R. L.: Comparing Reanalyses Using Analysis Increment Statistics, J. Hydrometeorol., 9, 1535-1545, 2008.

Fu, D., Bowman, K. W., Worden, H. M., Natraj, V., Worden, J. R., Yu, S., Veefkind, P., Aben, I., Landgraf, J., Strow, L., and Han, Y.: High-resolution tropospheric carbon monoxide profiles retrieved from CrIS and TROPOMI, Atmos. Meas. Tech., 9, 2567-2579, doi:10.5194/amt-9-2567-2016, 2016.

Galli, A., Butz, A., Scheepmaker, R. A., Hasekamp, O., Landgraf, J., Tol, P., Wunch, D., Deutscher, N. M., Toon, G. C., Wennberg, P. O., Griffith, D. W. T., and Aben, I.: $\mathrm{CH}_{4}, \mathrm{CO}$, and $\mathrm{H}_{2} \mathrm{O}$ spectroscopy for the Sentinel-5 Precursor mission: an assessment with the Total Carbon Column Observing Network measurements, Atmos. Meas. Tech., 5, 1387-1398, doi:10.5194/amt-51387-2012, 2012.

George, M., Clerbaux, C., Bouarar, I., Coheur, P.-F., Deeter, M. N., Edwards, D. P., Francis, G., Gille, J. C., Hadji-Lazaro, J., Hurtmans, D., Inness, A., Mao, D., and Worden, H. M.: An examination of the long-term CO records from MOPITT and IASI: com- 
parison of retrieval methodology, Atmos. Meas. Tech., 8, 43134328, doi:10.5194/amt-8-4313-2015, 2015.

Gloudemans, A. M. S., Schrijver, H., Hasekamp, O. P., and Aben, I.: Error analysis for $\mathrm{CO}$ and $\mathrm{CH}_{4}$ total column retrievals from SCIAMACHY $2.3 \mu \mathrm{m}$ spectra, Atmos. Chem. Phys., 8, 39994017, doi:10.5194/acp-8-3999-2008, 2008.

Hass, H., van Loon, M., Kessler, C., Stern, R., Matthijsen, J., Sauter, F., Zlatev, Z., Langner, J., Foltescu, V., and Schaap, M.: Aerosol modelling: Results and Intercomparison from European Regional-scale modelling systems, Special Rep. EUROTRAC-2 ISS, Munich, 2003.

HTAP: Hemispheric Transport of Air Pollution 2007, Air Pollution Studies No. 16. UN Publication, ECE/EB.AIR/94, Geneva, 2007.

Huijnen, V., Eskes, H. J., Poupkou, A., Elbern, H., Boersma, K. F., Foret, G., Sofiev, M., Valdebenito, A., Flemming, J., Stein, O., Gross, A., Robertson, L., D'Isidoro, M., Kioutsioukis, I., Friese, E., Amstrup, B., Bergstrom, R., Strunk, A., Vira, J., Zyryanov, D., Maurizi, A., Melas, D., Peuch, V.-H., and Zerefos, C.: Comparison of $\mathrm{OMI} \mathrm{NO}_{2}$ tropospheric columns with an ensemble of global and European regional air quality models, Atmos. Chem. Phys., 10, 3273-3296, doi:10.5194/acp-10-3273-2010, 2010.

Jacob, D. J.: Heterogeneous chemistry and tropospheric ozone, Atmos. Environ., 34, 2131-2159, 2000.

Kaiser, J. W., Heil, A., Andreae, M. O., Benedetti, A., Chubarova, N., Jones, L., Morcrette, J.-J., Razinger, M., Schultz, M. G., Suttie, M., and van der Werf, G. R.: Biomass burning emissions estimated with a global fire assimilation system based on observed fire radiative power, Biogeosciences, 9, 527-554, doi:10.5194/bg-9-527-2012, 2012.

Kuenen, J. J. P., Visschedijk, A. J. H., Jozwicka, M., and Denier van der Gon, H. A. C.: TNO-MACC_II emission inventory; a multiyear (2003-2009) consistent high-resolution European emission inventory for air quality modelling, Atmos. Chem. Phys., 14, 10963-10976, doi:10.5194/acp-14-10963-2014, 2014.

Kujanpää, J., Nijhuis, H. O., Eskes, H., de Haan, J., Veefkind, P., and Tamminen, J.: Synthetic Observation Product Specification (SOPS), Report of the ESA project "Impact of Spaceborne Observations on Tropospheric Composition Analysis and Forecast" (ISOTROP), 12 August 2015.

Lagarde, T., Piacentini, A., and Thual, O.: A new representation of data assimilation methods: the PALM flow charting approach, Q. J. Roy. Meteor. Soc., 127, 189-207, 2001.

Lahoz, W. A. and Schneider, P.: Data assimilation: making sense of earth observation, Front. Environ. Sci., 2, 16, doi:10.3389/fenvs.2014.00016, 2014.

Lahoz, W. A., Brugge, R., Jackson, D. R., Migliorini, S., Swinbank, R., Lary, D., and Lee, A.: An observing system simulation experiment to evaluate the scientific merit of wind and ozone measurements from the future SWIFT instrument, Q. J. Roy. Meteor. Soc., 131, 503-523, doi:10.1256/qj.03.109, 2005.

Lahoz, W. A., Errera, Q., Swinbank, R., and Fonteyn, D.: Data assimilation of stratospheric constituents: a review, Atmos. Chem. Phys., 7, 5745-5773, doi:10.5194/acp-7-5745-2007, 2007a.

Lahoz, W. A., Geer, A. J., Bekki, S., Bormann, N., Ceccherini, S., Elbern, H., Errera, Q., Eskes, H. J., Fonteyn, D., Jackson, D. R., Khattatov, B., Marchand, M., Massart, S., Peuch, V.-H., Rharmili, S., Ridolfi, M., Segers, A., Talagrand, O., Thornton, H. E., Vik, A. F., and von Clarmann, T.: The Assimilation of En- visat data (ASSET) project, Atmos. Chem. Phys., 7, 1773-1796, doi:10.5194/acp-7-1773-2007, 2007b.

Lahoz, W. A., Peuch, V.-H., Orphal, J., Attié, J.-L., Chance, K., Liu, X., Edwards, D., Elbern, H., Flaud, J.-M., Claeyman, and El Amraoui, L.: Monitoring air quality from space: the case for the geostationary platform, B. Am. Meteorol. Soc., 93, 221-233, doi:10.1175/BAMS-D-11-00045.1, 2012.

Landgraf, J., aan de Brugh, J., Scheepmaker, R., Borsdorff, T., Hu, H., Houweling, S., Butz, A., Aben, I., and Hasekamp, O.: Carbon monoxide total column retrievals from TROPOMI shortwave infrared measurements, Atmos. Meas. Tech., 9, 49554975, doi:10.5194/amt-9-4955-2016, 2016.

Lee, J. D., Lewis, A. C., Monks, P. S., Jacob, M., Hamilton, J. F., Hopkins, J. R., Watson, N. M., Saxton, J. E., Ennis, C., Carpenter, L. J., Carslaw, N., Fleming, Z., Bandy, B. J., Oram, D. E., Penkett, S. A., Slemr, J., Norton, E., Rickard, A. R., Whalley, L. K., Heard, D. E., Bloss, W. J., Gravestock, T., Smit, S. C., Stanton, J., Pilling, M. J., and Jenkin, M. E.: Ozone photochemistry and elevated isoprene during the UK heatwave of August 2003, Atmos. Environ., 40, 7598-7613, 2006.

Lefèvre, F., Brasseur, G. P., Folkins, I., Smith, A. K., and Simon, P.: Chemistry of the 1991-1992 stratospheric winter: three dimensional model simulations, J. Geophys. Res., 99, 8183-8195, 1994.

Levelt, P.: Observation Techniques and Mission Concepts for Atmospheric Chemistry (CAMELOT), ESA Study, Contract no. 20533/07/NL/HE, 2009.

Lord, S. J., Kalnay, E., Daley, R., Emmitt, G. D., and Atlas, R.: "Using OSSEs in the design of the future generation of integrated observing systems, 1st Symposium on Integrated Observing Systems (Long Beach, CA: American Meteorological Society), 1997.

Manders, A. M. M., Schaap, M., and Hoogerbruggem, R.: Testing the capability of the chemistry transport model LOTOS-EUROS to forecast $\mathrm{PM}_{10}$ levels in The Netherlands, Atmos. Environ., 43, 4050-4059, doi:10.1016/j.atmosenv.2009.05.006, 2009.

Marécal, V., Peuch, V.-H., Andersson, C., Andersson, S., Arteta, J., Beekmann, M., Benedictow, A., Bergström, R., Bessagnet, B., Cansado, A., Chéroux, F., Colette, A., Coman, A., Curier, R. L. Denier van der Gon, H. A. C., Drouin, A., Elbern, H., Emili, E., Engelen, R. J., Eskes, H. J., Foret, G., Friese, E., Gauss, M., Giannaros, C., Guth, J., Joly, M., Jaumouillé, E., Josse, B., Kadygrov, N., Kaiser, J. W., Krajsek, K., Kuenen, J., Kumar, U., Liora, N., Lopez, E., Malherbe, L., Martinez, I., Melas, D., Meleux, F., Menut, L., Moinat, P., Morales, T., Parmentier, J., Piacentini, A., Plu, M., Poupkou, A., Queguiner, S., Robertson, L., Rouïl, L., Schaap, M., Segers, A., Sofiev, M., Tarasson, L., Thomas, M., Timmermans, R., Valdebenito, Á., van Velthoven, P., van Versendaal, R., Vira, J., and Ung, A.: A regional air quality forecasting system over Europe: the MACC-II daily ensemble production, Geosci. Model Dev., 8, 2777-2813, doi:10.5194/gmd8-2777-2015, 2015.

Massart, S., Clerbaux, C., Cariolle, D., Piacentini, A., Turquety, S., and Hadji-Lazaro, J.: First steps towards the assimilation of IASI ozone data into the MOCAGE-PALM system, Atmos. Chem. Phys., 9, 5073-5091, doi:10.5194/acp-9-5073-2009, 2009.

Masutani, M., Schlatter, T. W., Errico, R. M., Stoffelen, A., Andersson, E., Lahoz, W., Woollen, J. S., Emmitt, G. D., Riishøjgaard, L.-P., and Lord, S. J.: Observing system simulation experiments. 
Data Assimilation: Making Sense of Observations, edited by: Lahoz, W. A., Khattatov, B., and Ménard, R., Springer, 647-679, 2010a.

Masutani, M., Woollen, J. S., Lord, S. J., Emmitt, G. D., Kleespies, T. J., Wood, S. A., Greco, S., Sun, H., Terry, J., Kapoor, V., Treadon, R., and Campana, K. A.: Observing system simulation experiments at the National Centers for Environmental Prediction, J. Geophys. Res., 115, D7, doi:10.1029/2009JD012528, $2010 b$.

Nitta, T.: Some analyses of observing systems simulation experiments in relation to First GARP Global Experiment, in: GARP Working Group on Numerical Experimentation, Report No. 10, US GARP Plan (Washington, DC), 1-35, 1975.

Ordóñez, C., Elguindi, N., Stein, O., Huijnen, V., Flemming, J., Inness, A., Flentje, H., Katragkou, E., Moinat, P., Peuch, V.-H., Segers, A., Thouret, V., Athier, G., van Weele, M., Zerefos, C. S., Cammas, J.-P., and Schultz, M. G.: Global model simulations of air pollution during the 2003 European heat wave, Atmos. Chem. Phys., 10, 789-815, doi:10.5194/acp-10-789-2010, 2010.

Peuch, V.-H., Amodei, M., Barthet, T., Cathala, M. L., Michou, M., and Simon, P.: MOCAGE, MOdéle de Chimie Atmosphérique à Grande Echelle, in: Proceedings of Météo France: Workshop on atmospheric modelling, 33-36, Toulouse, France, 1999.

Rodgers, C. D.: Inverse methods for atmospheric sounding: Theory and Practice, Series on Atmospheric, Oceanic and Planetary Physics - Vol. 2, Singapore, World Scientific, 2000.

Schaap, M., Timmermans, R. M. A., Roemer, M., Boersen, G. A. C., Builtjes, P. J. H., Sauter, F. J., Velders, G. J. M., and Beck, J. P.: The Lotos-Euros model: Description, validation and latest developments, Int. J. Environ. Pollut., 32, 270-290, 2008.

Semane, N., Peuch, V.-H., El Amraoui, L., Bencherif, H., Massart, S., Cariolle, D., Attié, J.-L., and Abida, R.: An observed and analysed stratospheric ozone intrusion over the high Canadian Arctic UTLS region during the summer of 2003, Q. J. Roy. Meteor. Soc., 133, 171-178, doi:10.1002/qj.141, 2007.

Solberg, S., Hov, Ø., Søvde, A., Isaksen, I. S. A., Coddeville, P., De Backer, H., Forster, C., Orsolini, Y., and Uhse, K.: European surface ozone in the extreme summer 2003, J. Geophys. Res., 113, D07307, doi:10.1029/2007JD009098, 2008.

Stockwell, W. R., Kirhcner, F., Kuhn, M., and Seefeld, S.: A new mechanism for regional atmospheric chemistry modeling, J. Geophys. Res., 102, 25847-25879, doi:10.1029/97JD00849, 1997.

Stoffelen, A., Marseille, G. J., Bouttier, F., Vasiljevic, D., DeHaan, S., and Cardinali, C.: ADM-Aeolus Doppler wind lidar observing system simulation experiment, Q. J. Roy. Meteor. Soc., 619, 1927-1948, doi:10.1256/qj.05.83, 2006.

Stern, R., Builtjes, P., Schaap, M., Timmermans, R., Vautard, R., Hodzic, A., Memmesheimer, M., Feldmann, H., Renner, E., Wolke, R., and Kerschbaumer, A.: A model inter-comparison study focussing on episodes with elevated $\mathrm{PM}_{10}$ concentrations, Atmos. Environ., 42, 4567-4588, doi:10.1016/j.atmosenv.2008.01.068, 2008.

Streets, D. G.: Emissions estimation from satellite retrievals: A review of current capability, Atmos. Environ., 77, 1011-1042, 2013.

Tan, D. G. H., Andersson, E., Fisher, M., and Isaksen, L.: Observing system impact assessment using a data assimilation ensemble technique: application to the ADM-Aeolus wind profiling mis- sion, Q. J. Roy. Meteor. Soc., 133, 381-390, doi:10.1002/qj.43, 2007.

Tangborn, A., Štajner, I., Buchwitz, M., Khlystova, I., Pawson, S., Hudman, R., and Nedelec, P.: Assimilation of SCIAMACHY total column $\mathrm{CO}$ observations: global and regional analysis of data impact, J. Geophys. Res., 114, D07307, doi:10.1029/2008JD010781, 2009.

Teyssèdre, H., Michou, M., Clark, H. L., Josse, B., Karcher, F., Olivié, D., Peuch, V.-H., Saint-Martin, D., Cariolle, D., Attié, J.-L., Nédélec, P., Ricaud, P., Thouret, V., van der A, R. J., VolzThomas, A., and Chéroux, F.: A new tropospheric and stratospheric Chemistry and Transport Model MOCAGE-Climat for multi-year studies: evaluation of the present-day climatology and sensitivity to surface processes, Atmos. Chem. Phys., 7, 58155860, doi:10.5194/acp-7-5815-2007, 2007.

Timmermans, R. M. A., Schaap, M., Elbern, H., Siddans, R., Tjemkes, S., and Vautard, R.: An Observing System Simulation Experiment (OSSE) for Aerosol Optical Depth from Satellites, J. Atmos. Ocean Tech., 26, 2673-2682, doi:10.1175/2009JTECHA1263.1, 2009a.

Timmermans, R. M. A., Segers, A. J., Builtjes, P. J. H., Vautard, R., Siddans, R., Elbern, H., Tjemkes, S., and Schaap, M.: The added value of a proposed satellite imager for ground level particulate matter analyses and forecasts, IEEE J. Sel. Top. Appl., 2, 271283, doi:10.1109/JSTARS.2009.2034613, 2009b.

Timmermans, R., Lahoz, W. A., Attié, J.-L., Peuch, V.-H., Curier, L., Edwards, D., Eskes, H., and Builtjes, P.: Observing System Simulation Experiments for Air Quality, Atmos. Environ., 115, 199-213, doi:10.1016/j.atmosenv.2015.05.032, 2015.

Tressol, M., Ordonez, C., Zbinden, R., Brioude, J., Thouret, V., Mari, C., Nedelec, P., Cammas, J.-P., Smit, H., Patz, H.-W., and Volz-Thomas, A.: Air pollution during the 2003 European heat wave as seen by MOZAIC airliners, Atmos. Chem. Phys., 8, 2133-2150, doi:10.5194/acp-8-2133-2008, 2008.

van Loon, M., Vautard, R., Schaap, M., Bergstrom, R., Bessagnet, B., Brandt, J., Builtjes, P. J. H., Christensen, J. H., Cuvelier, C., Graff, A., Jonson, J. E., Krol, M., Langner, J., Roberts, P., Rouïl, L., Stern, R., Tarrason, L., Thunis, P., Vignati, E., and White, L.: Evaluation of long-term ozone simulations from seven regional air quality models and their ensemble, Atmos. Environ. 41, 2083-2097, doi:10.1016/j.atmosenv.2006.10.073, 2007.

Vautard, R., Honoré, C., Beekmann, M., and Rouïl, L.: Simulation of ozone during the August 2003 heat wave and emission control scenarios, Atmos. Environ., 39, 2957-2967, 2005.

Veefkind, J. P., Aben, I., McMullan, K., Förster, H., de Vries, J., Otter, G., Claas, J., Eskes, H. J., de Haan, J. F., Kleipool, Q., van Weele, M., Hasekamp, O., Hoogeveen, R., Landgraf, J., Snel, R., Tol, P., Ingmann, P., Voors, R., Kruizinga, B., Vink, R., Visser, H., and Levelt, P. F.: TROPOMI on the ESA Sentinel-5 Precursor: A GMES mission for global observations of the atmospheric composition for climate, air quality and ozone layer applications, Remote Sens. Environ., 120, 70-83, 2012.

Vidot, J., Landgraf, J., Hasekamp, O. P., Butz, A., Galli, A., Tol, P., and Aben, I.: Carbon monoxide from shortwave infrared reflectance measurements: A new retrieval approach for clear-sky and partially cloudy atmospheres, Remote Sens. Environ., 120, 255, doi:10.1016/j.rse.2011.09.032, 2011.

Warner, J., Carminati, F., Wei, Z., Lahoz, W., and Attié, J.-L.: Tropospheric carbon monoxide variability from AIRS under clear 
and cloudy conditions, Atmos. Chem. Phys., 13, 12469-12479, doi:10.5194/acp-13-12469-2013, 2013.

Weaver, A. and Courtier, P.: Correlation modelling on the sphere using a generalized diffusion equation, Q. J. Roy. Meteor. Soc., 127, 1815-1846, 2001.

Willmott, C. and Matsuura, K.: Advantages of the Mean Absolute Error (MAE) over the Root Mean Square Error (RMSE) in assessing average model performance, Clim. Res., 30, 79-82, 2005.

Willmott, C., Matsuura, K., and Robeson, S. M.: Ambiguities inherent in sums-of-squares-based error statistics, Atmos. Environ., 43, 749-752, 2009.

Worden, H. M., Deeter, M. N., Frankenberg, C., George, M., Nichitiu, F., Worden, J., Aben, I., Bowman, K. W., Clerbaux, C., Coheur, P. F., de Laat, A. T. J., Detweiler, R., Drummond, J. R., Edwards, D. P., Gille, J. C., Hurtmans, D., Luo, M., MartínezAlonso, S., Massie, S., Pfister, G., and Warner, J. X.: Decadal record of satellite carbon monoxide observations, Atmos. Chem. Phys., 13, 837-850, doi:10.5194/acp-13-837-2013, 2013.
Yumimoto, K.: Impacts of geostationary satellite measurements on CO forecasting: an observing system simulation experiment with GEOS- Chem/LETKF data assimilation system, Atmos. Environ., 74, 123-133, doi:10.1016/j.atmosenv.2013.03.032, 2013.

Zoogman, P., Jacob, D. J., Chance, K., Zhang, L., Le Sager, P., Fiore, A. M., Eldering, A., Liu, X., Natraj, V., and Kulawik, S. S.: Ozone air quality measurement requirements for a geostationary satellite mission, Atmos. Environ., 45, 7143-7150, 2011.

Zoogman, P., Jacob, D. J., Chance, K., Liu, X., Lin, M., Fiore, A., and Travis, K.: Monitoring high-ozone events in the US Intermountain West using TEMPO geostationary satellite observations, Atmos. Chem. Phys., 14, 6261-6271, doi:10.5194/acp-146261-2014, 2014a.

Zoogman, P., Jacob, D. J., Chance, K., Worden, H. M., Edwards, D. P., and Zhang, L.: Improved monitoring of surface ozone by joint assimilation of geostationary satellite observations of ozone and CO, Atmos. Environ., 84, 254-261, doi:10.1016/j.atmosenv.2013.11.048, 2014b. 